\title{
Modeling the natural gas supply chain for sustainable growth policy
}

\author{
Mauricio Becerra-Fernandez ${ }^{\mathrm{a}}$, Federico Cosenz ${ }^{\mathrm{b}}$, Isaac Dyner ${ }^{\mathrm{c}}$ * \\ a Universidad Catolica de Colombia, Avenida Caracas \# 46 -72, Bogotá, Colombia \\ ${ }^{\mathrm{b}}$ University of Palermo, Via Maqueda n. 324, 90134, Palermo, Italy

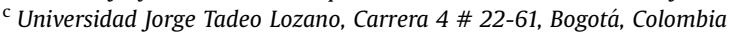

\section{A R T I C L E I N F O}

\section{Article history:}

Received 23 January 2020

Received in revised form 27 April 2020

Accepted 30 May 2020

Available online 8 June 2020

\section{Keywords:}

Policy design and assessment

Natural gas supply chain

Systems dynamics modeling

Case-study

Colombia

\begin{abstract}
A B S T R A C T
Natural gas has been used globally as a transitional fuel for supporting a green-energy-supply strategy, which has been questioned for the intermittence and lack of reliability of renewables. This paper proposes a System Dynamics model for assessing alternative security of supply policy along the natural gas value chain. The model incorporates demand, transport, production and reserves of natural gas variables according to a systemic perspective. It also includes a module for evaluating the effect of natural gas price on the demand and supply levels, respectively. Alternative supply policies are evaluated under different scenarios. The chosen case-study focuses on the Colombian natural gas industry with the purpose of assessing how the impact of public policies affect supply and demand. Particularly, policies consider the allocation of resources along the natural gas supply chain, seeking to promote the development of infrastructure oriented to mitigate the risk of provision shortages.
\end{abstract}

() 2020 Elsevier Ltd. All rights reserved.

\section{Introduction}

Renewable energy sources are essential as part of the green energy agenda worldwide [1]. Natural gas is also included - despite being considered a non-renewable energy source - because it is identified as a "low-carbon-emitter" for power generation and transport globally [2].

The reserves of natural gas increased 18.2\% between 2007 and 2017 worldwide, reaching 193.4 Trillion Cubic Meters [TCM] according to the following distribution: $40.9 \%$ in the Middle East, $30.6 \%$ in the Commonwealth of Independent States (CIS), $10.0 \%$ in Asia Pacific, 7.1\% in Africa, 5.6\% in North America, $4.2 \%$ in South and $1.6 \%$ in Central America and Europe. The production of natural gas between 2007 and 2017 raised 25.12\% worldwide, ranging from 2.94 to 3.68 [TCM], allocated as follows: North America 25.9\%, CIS $22.2 \%$, Middle East 17.9\%, Asia Pacific 16.5\%, Europe 6.6\%, and Africa 6.1\%, South and Central America 4.9\% [3]. In contrast, world

\footnotetext{
* Corresponding author.

E-mail addresses: mauriciobecerrafernandez@gmail.com, mbecerra@ucatolica. edu.co (M. Becerra-Fernandez), federico.cosenz@unipa.it (F. Cosenz), isaac. dynerr@utadeo.edu.co (I. Dyner).
}

consumption between 2007 and 2017 increased by 24.08\%, from 2.96 to 3.67 [TCM]. The reported share of energy consumption was: North America 25.7\%, Asia Pacific 21.0\%, CIS 15.7\%, the Middle East 14.6\%, Europe 14.5\%, South and Central America 4.7\% and Africa $3.9 \%[3]$.

As reserves of natural gas are declining rapidly in Colombia. The question is whether this fuel can help the transition towards renewables and how secure this may be. Between 2010 and 2016, natural gas reserves in Colombia showed an average annual change of $-6 \%$, decreasing from 7.1 to 5.3 Trillion Cubic Feet. Production showed a critical decrease between 2014 and 2017, with an average decrease of $-5.52 \%$, from 1153 to 955 Giga BTU per day [GBTUD], between 2014 and 2017. This contrasted with a demand increase of $3.4 \%$ between 2009 and 2015, showing significant reductions of gas reserves in the country [4].

As an indicator of reserve levels against the production of natural gas, the reserves-production per year ratio $(\mathrm{R} / \mathrm{P})$ establishes the number of years up to exhaustion. This ratio on a global level ranged from 62 in 2007 to 51 in 2017, according to the following distribution: Middle East 120, CIS 73, Africa 61, South and Central America 46, Asia Pacific 32, Europe 12 and North America 11 [3]. In Colombia, the indicator moved from 18.1 in 2010 to 12.6 in 2017, estimating that, with the current reserves and at the same production rate, it will reach 0.8 by the year 2030 [4]. 
The production of electricity in Colombia depends largely on hydroelectricity, and also on thermal generation using natural gas and coal. The reported capacity in place in 2018 was 17720 megawatts [MW], with a $70 \%$ share of water sources, $9 \%$ of natural gas, $9 \%$ of coal and 7\% ACPM [5]. Colombia is affected by a recurrent climatic phenomena called "El Niño", which is characterized by dry periods or droughts, that reduce river flow-levels, threatening hydroelectricity production in the country. Given its lower environmental impacts and costs as opposed to the use of coal [6], thermal generation through natural gas is considered as a source of support for the energy system during those periods when this phenomenon occurs [4].

In addition, through the analysis of demand scenarios, the Mining and Energy Planning Unit of Colombia (known as UPME) highlights a potential deficit in the supply of the resource by February 2024, thereby indicating that the country needs to make prompt decisions to achieve a sustainable supply setting [7].

Against this background, exploring the mechanisms underlying the natural gas supply in Colombia is considered of great importance in terms of government policy design. Emerging policies point to the transition to clean energy sources and to reliably support the power industry, thus offering a greater contribution to the environmental sustainability through the reduction of $\mathrm{CO}_{2}$ emissions, the decrease in consumer price, which also fosters the economic and competitive development of the country. In this context, this paper poses the following research question: What are the capacity levels of production facilities and natural gas transport networks adequate to guarantee an uninterrupted supply of natural gas in Colombia?

In this context, the system dynamics (SD) approach was chosen for addressing the above research question. SD has been widely used for alternative policy assessment [8-15]. The main advantage of SD is that it explains endogenously how the system evolves over time through the feedback of causes and effects [16,17]. Its system perspective is particularly relevant when alternative future scenarios are considered, as it is the case in this research. This methodological approach can not only model highly complex systems but also facilitates policy and strategy design for managing system change.

This paper is organized as follows: first, the literature review is presented and the main critical issues of this research are identified. Next, in the modeling section, the research hypothesis is discussed through the analysis of causal loop diagrams and stocks and flows structures. Subsequently, the model variables and associated input parameters are framed and causally connected, thereby validating the emerging SD model. The results section analyses the behavior of the system under three simulation scenarios that combine variables upon which public policy makers (i.e., national government) can intervene in the supply of the analyzed resource. Eventually, conclusions are discussed summing up the main contributions of studying the natural gas supply chain through the relationship between demand, transport, and production.

\section{Literature review}

The software Tree of Science has been used for conducting the background analysis. Such software performs a narrative search, analysis of citation patterns (networks) and meta-analysis, classifying the articles in classic articles (root), structural articles (trunk) and recent articles (leaves) [18]. The literature review is based on the most relevant research carried out from the following perspectives: modeling natural gas supply chain policies and the application of SD methodology in the natural gas supply.

\subsection{Modeling natural gas supply chains policies}

Some research highlighted in terms of the design and planning of resources in the shale gas supply chain, using mathematical models of optimization $[19,20]$. Other research is also relevant in the study of the design and optimal planning of the supply chain of biomass-to-liquids (BTL) considering economic and environmental criteria through the application of a model of optimization [21].

In terms of structural articles, reviews analyze the research and mathematical models applied to the performance and optimal design of energy supply chains (shale gas case in the latter). They remark on the relevance of the geographical location of the facilities on the economic, environmental and social impact, in addition to the importance of optimization models in the study of energy systems [22,23]. Research related to the design, planning and optimization of the shale gas supply chain network, mainly consider environmental issues [24,25]. These papers use optimization and simulation methods. It is worth considering the research on planning activities focused on natural gas supply chain networks at several levels (i.e., strategic, tactical and operational), where optimization models are mainly used to reduce costs and facilitate an effective allocation of resources across the supply chain [26-29].

The most recent articles can be classified in those related to Bioenergetics, Liquefied Natural Gas (LNG), Shale Gas and Natural Gas. In the field of bioenergetics, some research contributions are significant [30-33]. There, the design and optimization of biomass, biogas, biodiesel and, biomethane supply chain networks are analyzed through economic and optimization models. Other research suggests the supply of Green gas as an alternative to natural gas for seasonal demands, using an optimization model [34]. In the strategic planning process among the actors of the supply chain, as well as in the design of strategies for importing and ensuring the supply of Liquefied Natural Gas (LNG) through comparative and optimization models. Some investigations are quite valuable [35-38]. In the case of shale gas, there is research on supply chain planning, investment in infrastructure, allocation of resources and reduction of environmental impact, in which utility optimization models are used for sustainability purposes [39-43]. From a more systemic perspective, some models in the fossils fuels field for decision making by operators and investors, use an integrated approach $[44,45]$.

Specifically, in the exploration of natural gas supply chains, some studies are of great interest. For instance, a literature review related to the effective use of natural gas supply chain mapping has been developed [46]. A Dynamic Upstream Gas Model [47] and the use of a probabilistic model [48] have been proposed for understanding the emissions and environmental effects of the natural gas supply. By adopting a Montecarlo model, some authors analyzed the supply chain in which natural gas is managed to generate electricity [49]. The allocation of capacities and infrastructure in the supply of natural gas through optimization models is also analyzed $[50,51]$. Studies on the infrastructure for transportation and distribution of natural gas are developed [52,53], while others consider the effects of the demand for the helium supply chain, through mixed-integer linear programming models [54].

As it is observed, the developed research contributions regarding the problem of energy supply and especially natural gas are mostly conducted by means of optimization modeling applied to the supply chain. Alternative approaches may benefit from the assessment of the supply of natural gas, through the coordination and integration of capacity decisions, thus addressing issues related to the timely attention of consumer's demand. Appendix A (see Table 6). shows a summary of the above-mentioned literature review. 


\subsection{System dynamics applied to the natural gas supply}

SD methodology has been used to explore the supply of energy sources. The extant research studies on this topic are shown below, with the aim to illustrate the investigations in this field and identify the gaps associated with the natural gas supply by using this approach.

Among the main studies related to the adoption of SD for the supply of natural gas, it is worth mentioning the research contributions [55-57]. Other research pieces have addressed the study of the energy market and natural gas using SD [58-60]. The SD methodology has proved to be useful for supporting policy and decision-making processes $[12,15,61,62]$. Some studies also consider the environmental impact of energy supply [63-66]. In other research close to the purposes of this paper, SD models for assessing the natural gas supply have been discussed [8-11].

Once the relevant literature has been mentioned, main findings reveal that policy opportunity has not been assessed for the gas industry through the combination of supply chain management approach and SD, which is the focus of this research, thus making a novel contribution for evaluating the potential effects of public policies on the sustainable supply of natural gas. Appendix B (see Table 7) includes a summary of the literature review on SD modeling applied to power supply.

\section{System dynamics modeling of the natural gas supply chain}

This section shows a natural gas supply chain SD model for the Colombian case, which we can use to identify the impact of public policies and how the main actions in terms of capacity expansion may meet the demand over time.

\subsection{Model conceptualization}

In the conceptualization of the SD model, the main operations forming the supply of natural gas are identified in Fig. 1. Namely, they are: reserves (proven, probable and possible), production, transport and demand (includes the electricity generation and nongeneration sectors) [67].

\subsection{Causal loop diagram (CLD)}

The following approaches were used for the formulation of the research hypothesis on which the proposed model is based: the supply and demand model [68], the analysis of policies for emission mitigation [69], the supply chain modeling [70], and the assessment of public policies for the supply of natural gas [8-10]. The research hypothesis is explained below and shown in Fig. 2. The description of the variables included are shown in Table 1.
- The modeling of the supply of natural gas considers the relationship demand, transport, production and reserves (like a supply chain), and enables us to observe the effect of the resources allocated in transport capacity, production capacity and reserves development through public policies implementation, instead of planning and supplying the domestic consumption sectors individually.

Fig. 2 exhibits the feedback loops used in the model and is explained below:

- Demand loop: increasing the demand generates a decrease in the supply margin of natural gas. An increase in the supply margin produces a reduction in the consumer price, which increases the natural gas demand. In addition, an increase in demand generates a signal in the supply for a decrease in the reserve capacity.

- Transport loop: increasing the consumer price encourages new transport capacity, with some delay due to the implementation time. When transport capacity increases, an increase in supply margin is induced (triggered, spurred). An increase in transport capacity produces increases in the supply margin.

- Production loop: a change in wellhead price encourages the construction of new capacity in natural gas production, which increases the production capacity over time. Increases in production capacity reduce the extraction margin which, in turn, increase the wellhead price.

- Reserves loop: the wellhead price encourages exploration of new reserves. Allowing for a time lag for exploration, the reserve capacity increases. An increase in reserves leads to an increase in the extraction margin, thus affecting the wellhead price.

\subsection{Stocks and flows diagram}

The stocks and flows diagram is based on the approach of Becerra et al. [8-10] (see Fig. 3). Additionally, the equations of the model developed through the software iThink can be seen in Appendix $C$ and explained below.

The stock variables represent fluctuations in the levels of natural gas reserves in order to meet the customer demand. The unit of measure used in the stocks is Giga Cubic Feet [GCF]. The first stock is presented, the others can be deduced from the stocks and flows diagram described (see Fig. 3), which corresponds to the possible reserves $(P R)$, representing the estimated volume of natural gas that has not been explored.

$\frac{d P R}{d t}=N R D-R D$

Where $(N R D)$ represents the new reserves development and $(R D)$ represents the reserves development, which generates an increase in the reserve capacity.
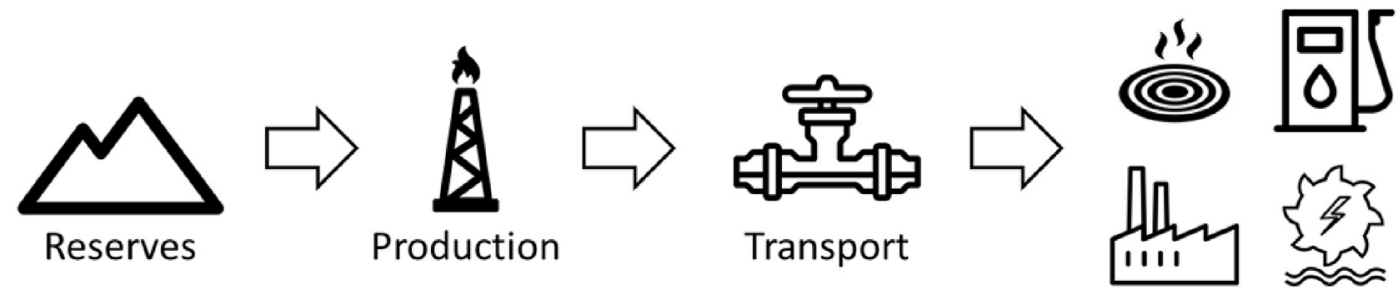

Demand

Fig. 1. Conceptualization of the model. 

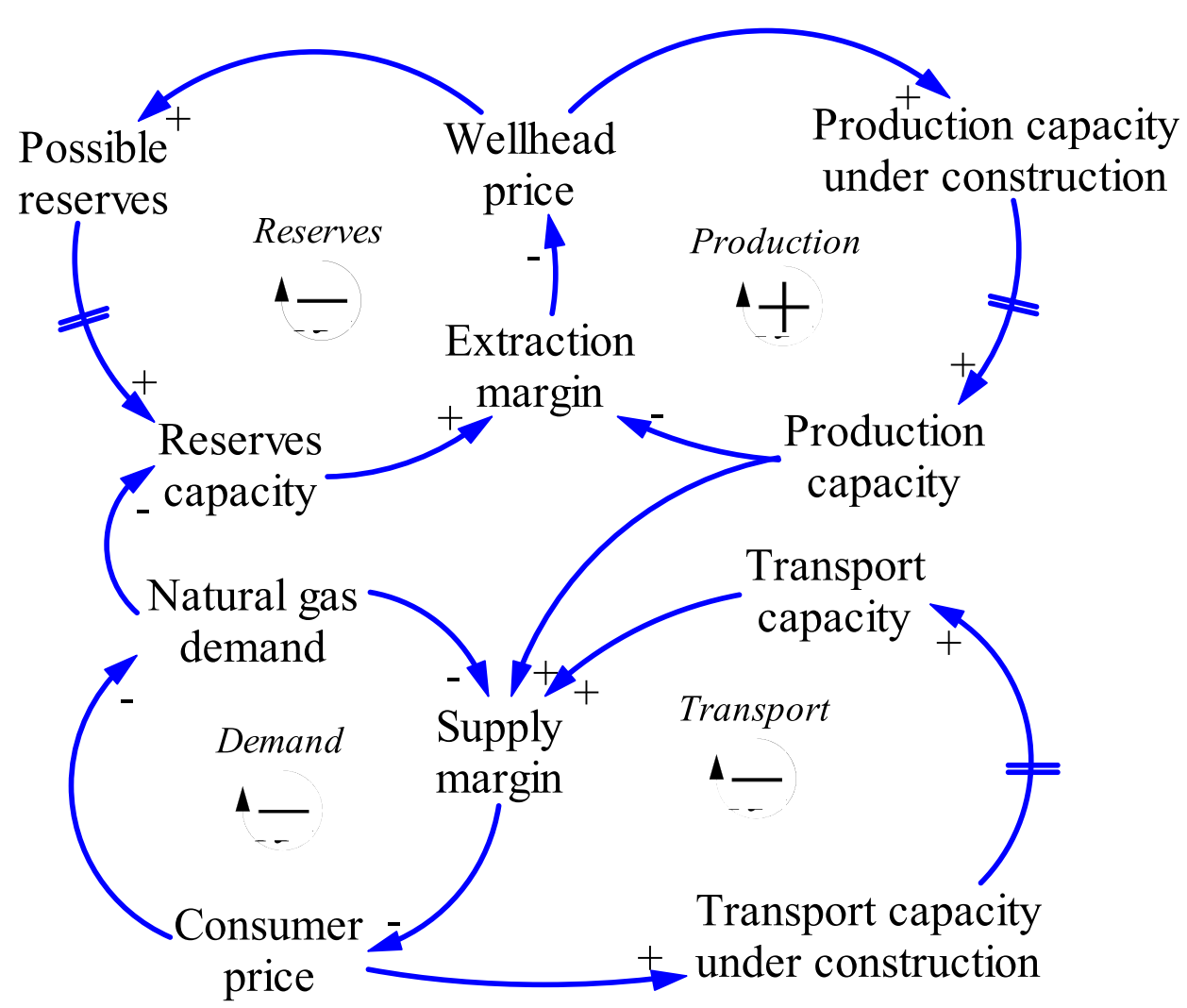

Fig. 2. Causal loop diagram (CLD) of the model.

$N R D=A R C I \cdot E W P R$

$$
R D=\frac{P R}{T R D}
$$

The historical average reserve capacity increase is represented as $(A R C I)$, while (EWPR) represents the effect of the wellhead price on reserve capacity, as shown in Fig. 4. (TRD) corresponds to the time for the development or exploration of new reserves.

The reserves capacity $(R C)$ represents the volume of gas reserves available in the country. These are consistent with the goals set by the reserves policies $(R P)$ and the consequent investment increases in new reserve development $(R D)$ (through new exploration and reserves development projects, as described in Table 4 ). This level variable $(R C)$ is reduced by obsolescence $(O R C)$, considering its given lifetime $(R C L)$.

$$
O R C=\frac{R C}{R C L}
$$

The wellhead price (WP) is the natural gas price considering the extraction and the production (see Fig. 5), which is based on the extraction margin (EM).

$E M=\frac{P R+R C}{P C U C+P C}$

The production capacity under construction is represented as $(P C U C)$, while $(P C)$ represents the total production capacity of the supply chain. Whereas (NPCC) represents the construction of new capacity in production, $(P C C)$ represents the completion of production capacity.

$N P C C=A P C I \cdot E W P P$

Table 1

\begin{tabular}{|c|c|c|}
\hline Feedback loop & Variable & Description \\
\hline \multirow[t]{2}{*}{ Reserves } & Possible reserves & Natural gas reserves with a probability of extraction. \\
\hline & Reserves capacity & Developed natural gas reserves, available for production. \\
\hline \multirow[t]{2}{*}{ Reserves and Production } & Extraction margin & Ratio between reserve levels and production levels. \\
\hline & Wellhead price & Price of natural gas at the point of extraction, affected by the extraction margin. \\
\hline Production & $\begin{array}{l}\text { Production capacity under construction } \\
\text { Production capacity }\end{array}$ & $\begin{array}{l}\text { Generation of production capacity, considering the time for the construction of new infrastructure. } \\
\text { Natural gas production capacity in the supply chain. }\end{array}$ \\
\hline Transport & $\begin{array}{l}\text { Transport capacity under construction } \\
\text { Transport capacity }\end{array}$ & $\begin{array}{l}\text { Generation of transport capacity, considering the time for the construction of new infrastructure. } \\
\text { Natural gas transport capacity (interconnected national networks). }\end{array}$ \\
\hline Transport and Demand & $\begin{array}{l}\text { Supply margin } \\
\text { Consumer price }\end{array}$ & $\begin{array}{l}\text { Ratio between supply capacities (production and transport) and demand levels. } \\
\text { Price of natural gas at the point of extraction, affected by the extraction margin. }\end{array}$ \\
\hline Demand & Natural gas demand & Price of natural gas to the consumer, affected by the supply margin. \\
\hline
\end{tabular}

Description of the variables included in CLD. 


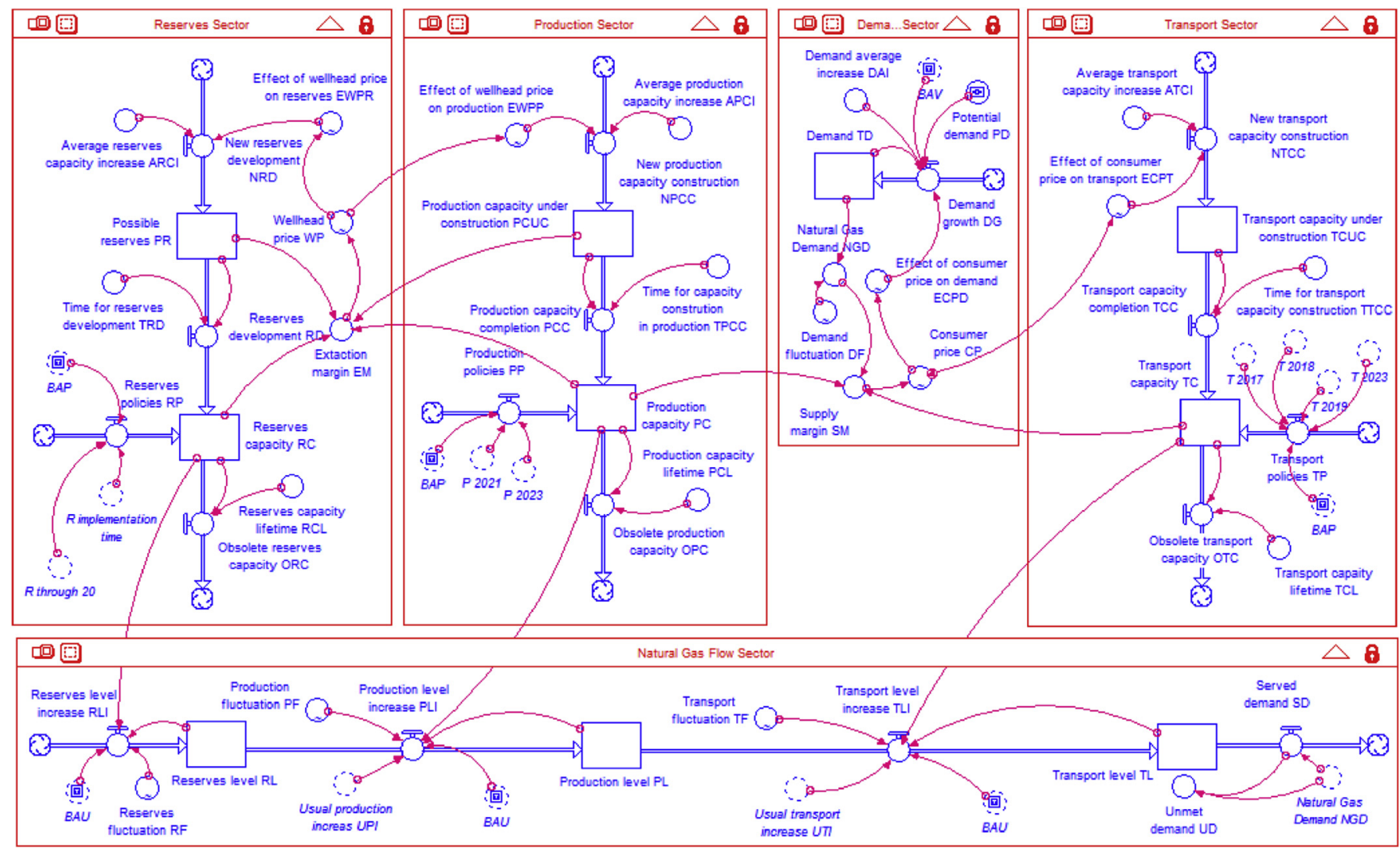

Fig. 3. Stocks and flows diagram of the model.

$$
P C C=\frac{P C U C}{T P C C}
$$

The historical average production capacity increase is represented as (APCI), while (EWPP) represents the effect of the wellhead price on production, as shown in Fig. 6. (TPCC) corresponds to the time for the implementation of new production capacity projects.

The production capacity $(P C)$ is the volume of production that the country can supply, which is calculated by adding (see Table 4): a) the increase in the production capacity completion of infrastructure projects $(P C C)$ and $\mathrm{b}$ ) the increase in the production policies $(P P)$, through the implementation of new production

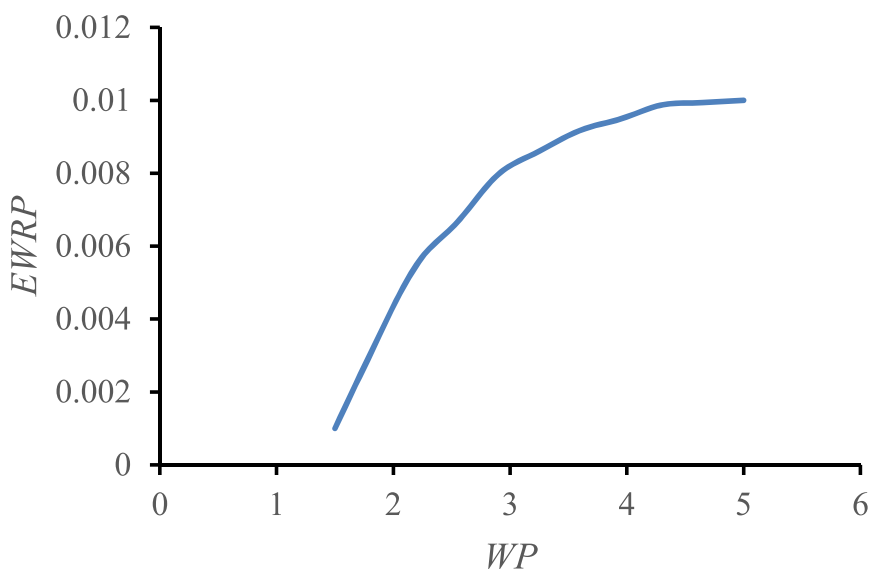

Fig. 4. EWRP graphical behavior. projects. This level variable $(P)$ is reduced by obsolescence $(O P C)$ considering a lifetime $(P C L)$. The transport capacity under construction is represented as (TCUC).

$O P C=\frac{P C}{P C L}$

(NTCC) represents the construction of new capacity in transport, and (TCC) represents the completion of transport capacity.

$N T C C=A T C I \cdot E C P T$

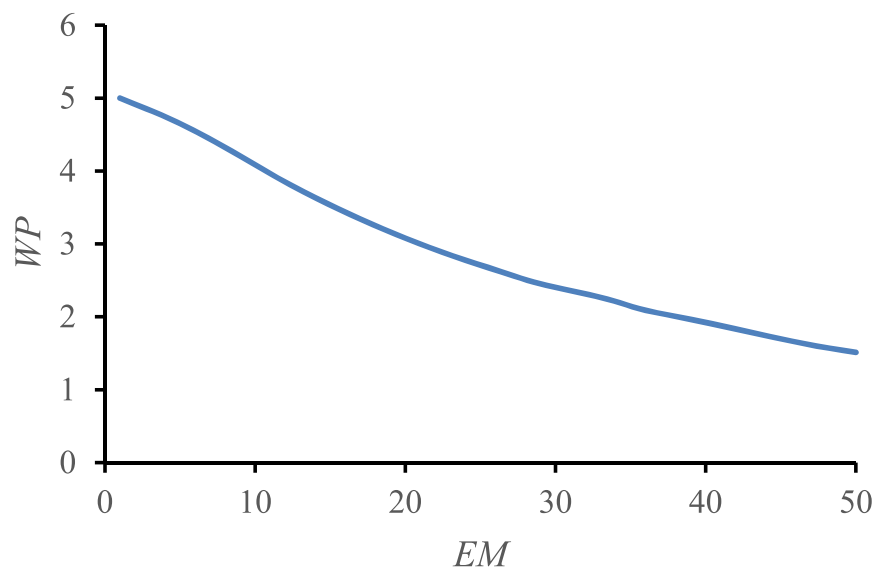

Fig. 5. WP graphical behavior. 


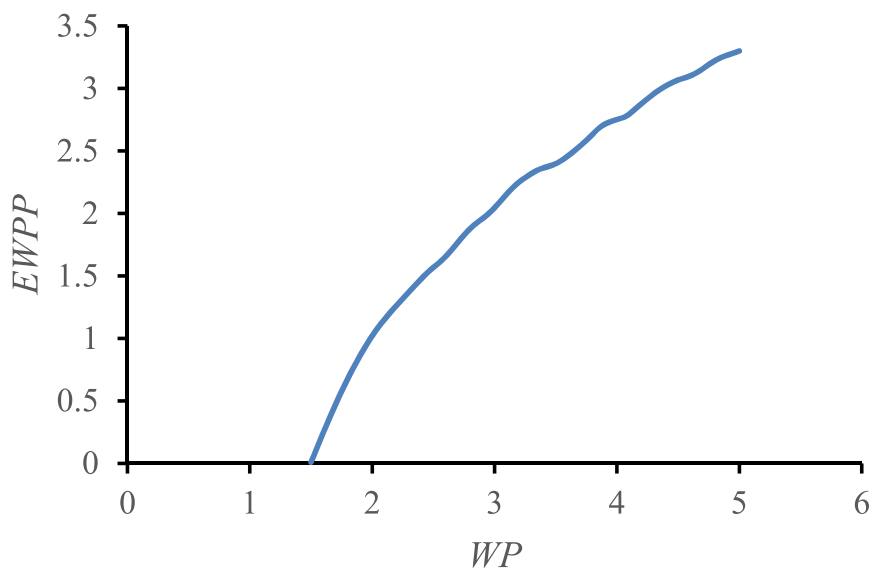

Fig. 6. EWPP graphical behavior.

$T C C=\frac{T C U C}{T T C C}$

The historical average transport capacity increase is represented as $(A T C I)$, and $(E C P T)$ represents the effect of consumer price on transport, as shown in Fig. 7. (TTCC) corresponds to the time for the implementation of new projects.

The transport capacity (TC) is the volume of transport that the country can supply. This includes the increase in the transport capacity completion of infrastructure projects (TCC) and the increase in the transport policies (TP), through the implementation of new transport projects as described in Table 4 . This level variable (TC) is reduced by obsolescence $(O T C)$ considering a lifetime $(T C L)$.

$O T C=\frac{T C}{T C L}$

Consumer price $(C P)$ is influenced by the demand (see Fig. 8), which is based on the supply margin $(S M)$.

$S M=\frac{(P C+T C) / 2}{D}$

The total demand of natural gas is represented as (TD), where $(D G)$ represents the demand growth.

$D G=D A I \cdot P D \cdot E C P D$

The historical average demand increase is represented as (DAI),

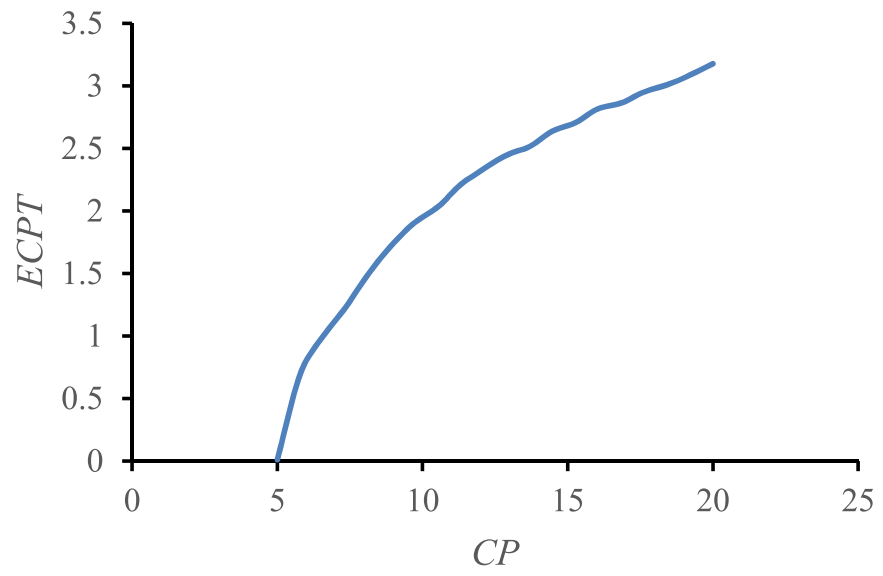

Fig. 7. ECPT graphical behavior.

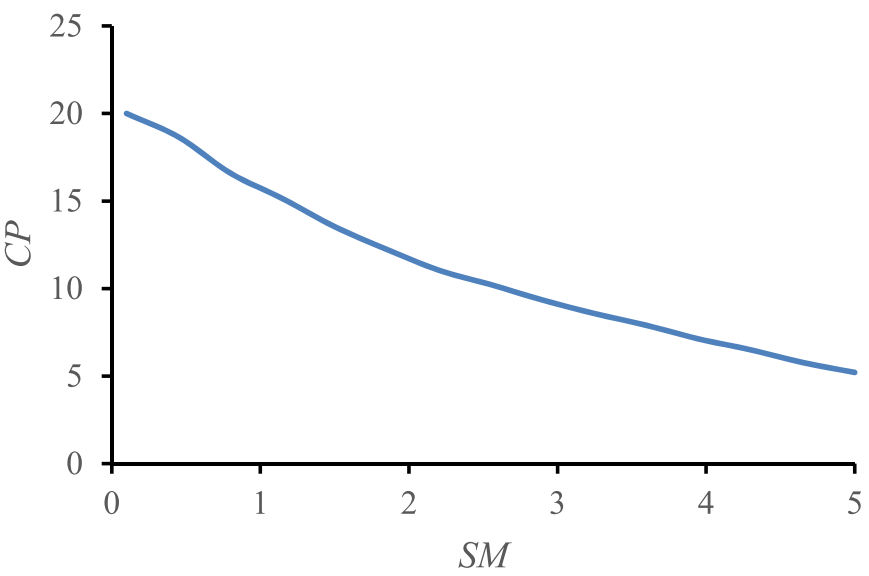

Fig. 8. CP graphical behavior.

(PD) represents the potential demand at the time. Additionally, $(E C P D)$ represents the effect of consumer price on demand, as shown in Fig. 9.

For the analysis of the natural gas flow in the supply chain, the model presents the level of reserves $(R L)$, the level of production $(P L)$ and the level of transport $(T L)$. Each of them are causally connected. While $(R L I)$ represents the increase in the reserve level, $(P L I)$ represents the increase in the production level. The transport level increase is represented as (TLI), and the served demand is represented as $(S D)$. In some cases, these flow variables consider the usual production increase (UPI) and the usual transport increase (UTI), or without the implementation of new infrastructure projects.

$R L I=\left\{\begin{array}{cc}R C>R L & R C-R L \\ 0 & \text { otherwise }\end{array}\right.$

$P L I=\left\{\begin{array}{cc}P C>P L & \max (P C, U P I) \\ 0 & \text { otherwise }\end{array}\right.$

$T L I=\left\{\begin{array}{cc}T C>T L & \max (T C, U T I) \\ 0 & \text { otherwise }\end{array}\right.$

$S D=T D$

Finally, the unmet demand $(U D)$ is calculated as a performance

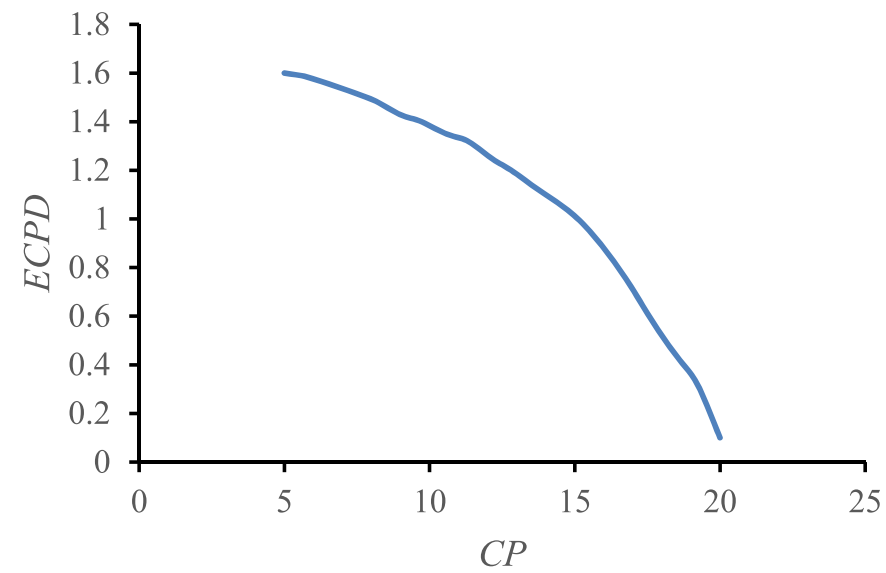

Fig. 9. ECPD graphical behavior. 


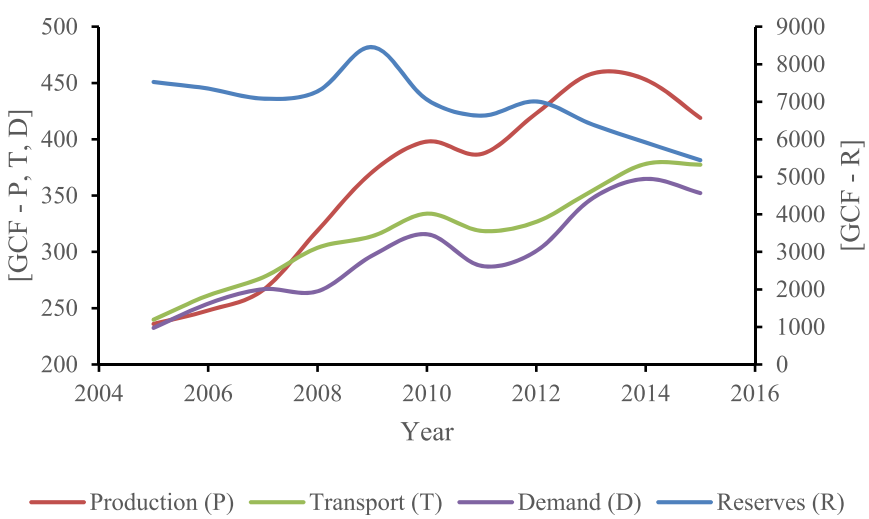

Fig. 10. Time series of natural gas in Colombia $[4,5,7,72]$.

measure, this is expected to be zero given the government's interest in maintaining a steady supply of natural gas.

$U D=\left\{\begin{array}{cc}T D-S D<0 & 0 \\ T D-S D & \text { otherwise }\end{array}\right.$

As SD models usually represent a theory of behavior [71], in the case of the natural gas supply chain industry these are supported by stocks and flows diagrams. The SD approach often follows to: the calibration and validation of the model, and several simulation runs evaluate policy under different scenarios.
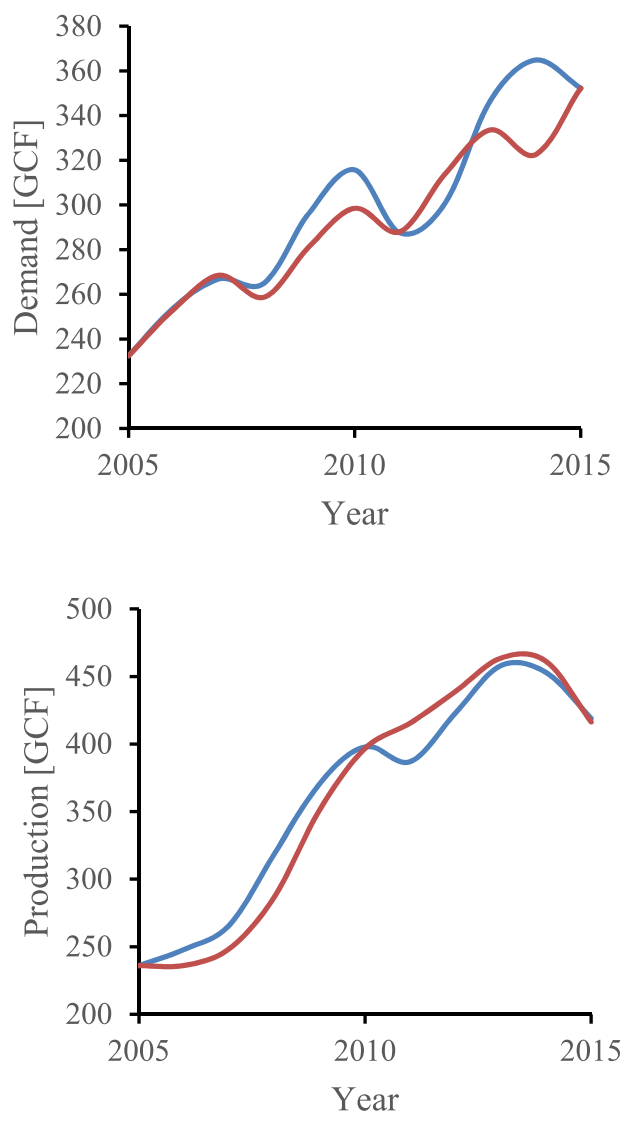

Historical data

\subsection{Calibration and validation}

In the calibration stage, the analysis of the units of measurement used was applied. The calibration process used historical data from UPME [4,5,7] and Ecopetrol (Colombian hydrocarbons company) [72] (see Fig. 10).

Through calibration, the behavior of the main variables of the model was observed, concerning the historical values presented above (see Fig. 11). The values of the parameters are shown in Table 2.

Eventually, in the calibration process, the forecast errors were used, thus remarking that the SD model correctly represents the natural gas supply (see Table 3 ).

\subsection{Scenario analysis in the natural gas model of demand, transport, and production}

In the Transitory Natural Gas Supply Plan [4], the national government of Colombia presents an instrument for assessing the supply and demand of this resource through the implementation of infrastructure projects. In this document, the government proposes projects for enhancing infrastructures that expand production. Transport capacities are defined for thirty-five years (see Table 4), in the case of production capacity in 307 [GCF], in terms of transport capacity in 281 [GCF] (see Fig. 12), with an estimated cost of $400 \mathrm{MM}$ [USD] for the expansion in production, and of $347 \mathrm{MM}$ [USD] for the expansion in transport [4].

The SD model applied to the Colombian case. A scenario analysis
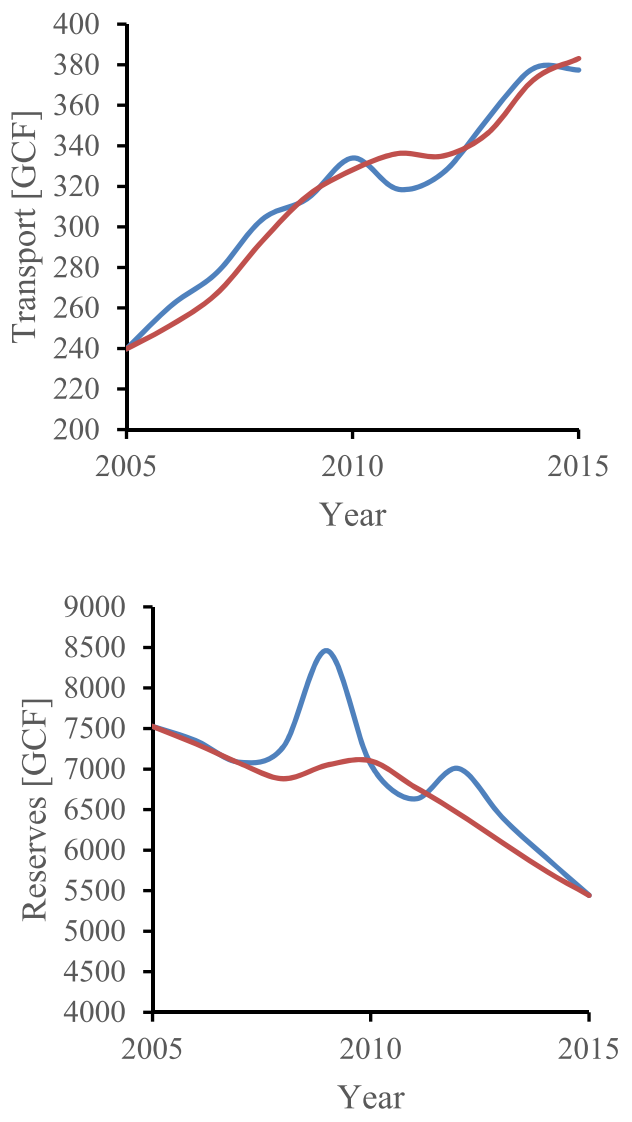

Simulation results

Fig. 11. Comparison between historical data and simulation results. 
Table 2

Data and parameters list.

\begin{tabular}{lll}
\hline Description & Unit of measure \\
\hline Reserves capacity initial value $(R C)$ & GCF \\
Production capacity initial value $(P C)$ & 7735 \\
Transport capacity initial value $(T C)$ & 236 \\
Total demand initial value $(T D)$ & 239 \\
Average reserves capacity increase $(A R C I)$ & 232 \\
Average production capacity increase $(A P C I)$ & $(208)$ \\
Average transport capacity increase $(A T C I)$ & 18 \\
Demand average increase $(D A I)$ & 13 \\
Time for reserves development $(T R D)$ & Percentage \\
Time for capacity construction in production $(T P C C)$ & Year \\
Time for transport capacity construction $(T T C C)$ & $6.14 \%$ \\
Reserves, production and transport capacity lifetime $(R C L),(P C L),(T C L)$ & 3 \\
\hline
\end{tabular}

Table 3

Forecast errors (summary).

\begin{tabular}{llllll}
\hline Variable & MSE & RMSE & MAD & MAPE & Accuracy \\
\hline Demand & 246 & 16 & 10 & $3.1 \%$ & $96.9 \%$ \\
Transport & 77 & 9 & 7 & $2.4 \%$ & $97.6 \%$ \\
Production & 274 & 17 & 13 & $3.8 \%$ & $96.2 \%$ \\
Reserves & 236815 & 487 & 280 & $3.8 \%$ & $96.2 \%$ \\
\hline
\end{tabular}

has been carried out to observe the behavior of the main actors/ operations intervening in the supply of this resource over twenty years. It considers the impact of government intervention, facing supply challenges, which enables us to analyze the upstream effects in the supply chain of natural gas, in order to provide elements for a sustainable supply policy. Three scenarios are presented (see Table 5), and explained below:

- Business as Usual (BAU): in this base-case scenario the supply continues without an increase in infrastructure.

- Business as Policies (BAP): in this scenario, the projects for the implementation of reserve development, imported natural gas through regasification plants, new gas pipelines, new stretches

Table 4

Infrastructure projects.

\begin{tabular}{lll}
\hline Stakeholders & Expected increase in capacity (GCF) & Year of implementation \\
\hline Reserves & 1040 & Trough 20 years \\
& 3000 & \\
Production & 16000 & 2023 \\
& 146 & 2021 \\
Transport & 17.2 & 2019 \\
& 27.1 & \\
& 45.9 & 2017 \\
& 20.9 & 2019 \\
& 47.5 & \\
& 29.6 & 2017 \\
& 6.7 & 2023 \\
46.9 & 2018 \\
& 31.3 & \\
& 7.0 & \\
& 0.9 & \\
\hline
\end{tabular}

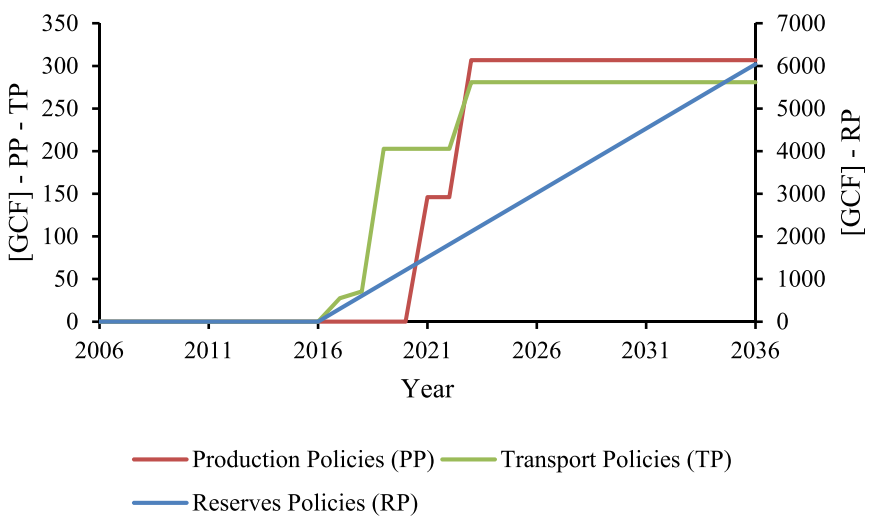

Fig. 12. Capacity expansion through reserves exploration and infrastructure projects in production and transport.

and flows in transport are considered (see Table 4 and Fig. 12), thus representing an increase in the national supply capacity.

- Business as Vision (BAV): the natural gas market in Colombia has not developed extensively. Given its low cost, the low impact on the environment and the possibility of finding a greater number of reserves, it is considered as a transition fuel between fossil energy sources and sources of renewable energy. In this scenario, it is expected to observe the behavior of natural gas supply, considering a policy implementation and a significant increase in demand.

\subsection{Results and discussion}

The results of the mentioned scenarios are presented and relate to the following variables:

Table 5

Scenarios of the model.

\begin{tabular}{llll}
\hline Changes included/Scenario & BAU & BAP & BAV \\
\hline Supply policies & & $\bullet$ & $\bullet$ \\
Market development & & & $\bullet$ \\
\hline
\end{tabular}




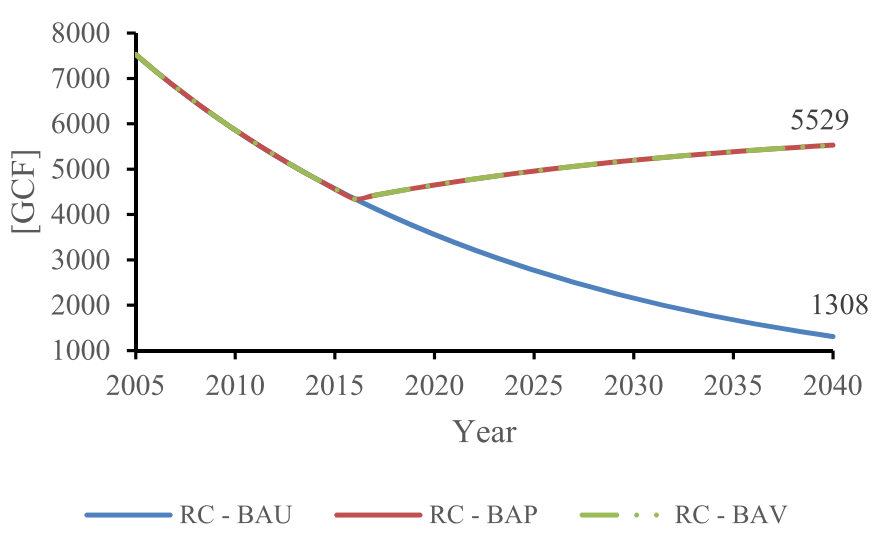

Fig. 13. Behavior of reserves capacity $(R C)$ under three different scenarios.

- Capacity variables: reserves capacity $(R C)$, production capacity $(P C)$ and transport capacity (TC).

- Natural gas flow variables: reserves level $(R L)$, production level $(P L)$ and transport level $(T L)$.

- Demand variables: total demand (TD), served demand (SD) and unmet demand (UD).

\subsubsection{Capacity variables}

These variables represent the capacity needs generated by the natural gas supply chain, considering the interactions between the supply and demand of each of the actors/operation involved in this supply.

The reserve capacity $(R C)$ in the BAU scenario is constantly decreasing, and reaches 1308 [GCF] in the year 2040. The BAP and BAV scenarios consider the implementation of exploration projects and the generation of new reserves from 2017, which represents an increase in this capacity to the year 2040 reaching 5529 [GCF] (see Fig. 13).

The production capacity $(P C)$ in the BAU scenario reaches a value of 934 [GCF] in the year 2040. For the BAP and BAV scenarios, this capacity reaches a value of 1031 [GCF] in the year 2040, in response

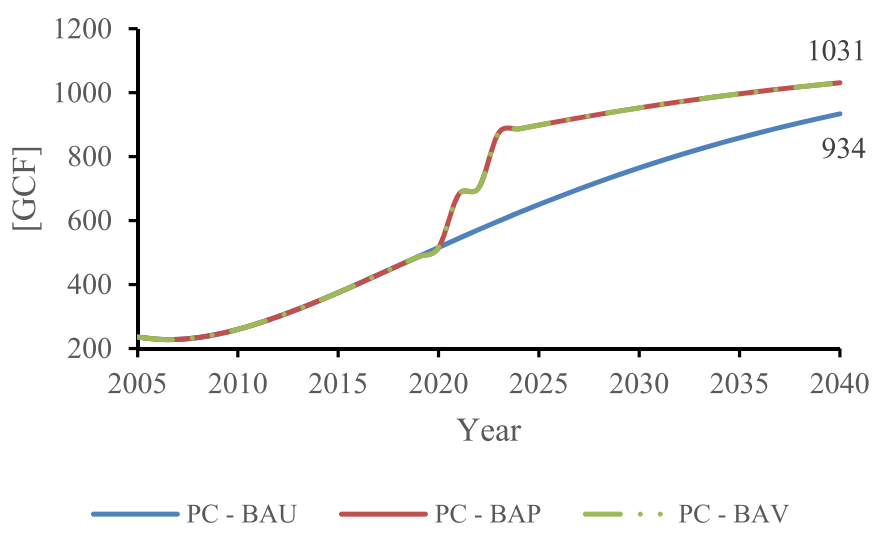

Fig. 14. Behavior of production capacity $(P C)$ under three different scenarios.
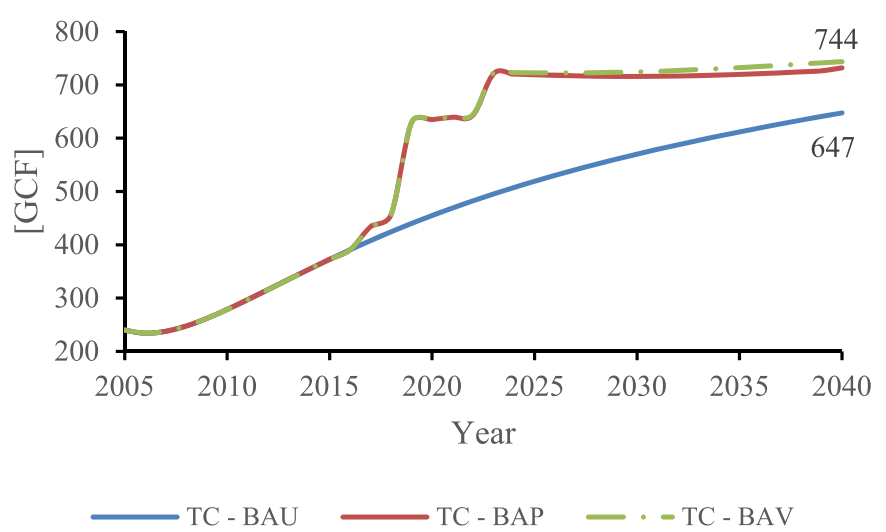

Fig. 15. Behavior of transport capacity (TC) under three different scenarios.

to the infrastructure projects in production implemented in the years 2021 and 2023 (see Fig. 14).

The transport capacity $(T C)$ in the BAU scenario reaches a value of 647 [GCF] in the year 2040. For the BAP and BAV scenarios, this capacity reaches an approximate value of 744 [GCF] in the year 2040, which corresponds to the transport infrastructure projects implemented between 2017 and 2023 (see Fig. 15).

\subsubsection{Natural gas flow variables}

These variables represent the flow of natural gas through the interconnected supply chain. They consider the dispatch of natural gas from the level of reserves, through the level of production and the level of transport, where the latter variable responds to the demand needs.

In the BAU scenario, the reserve level is constantly decreasing and reaches zero in 2025, generating a shortage. In the BAP and BAV scenarios, given the implementation of the new reserve development policies, a level of 4293 [GCF] is reached in the year 2040 (see Fig. 16).

Due to the depletion of the level of reserves $(R L)$ in the BAU

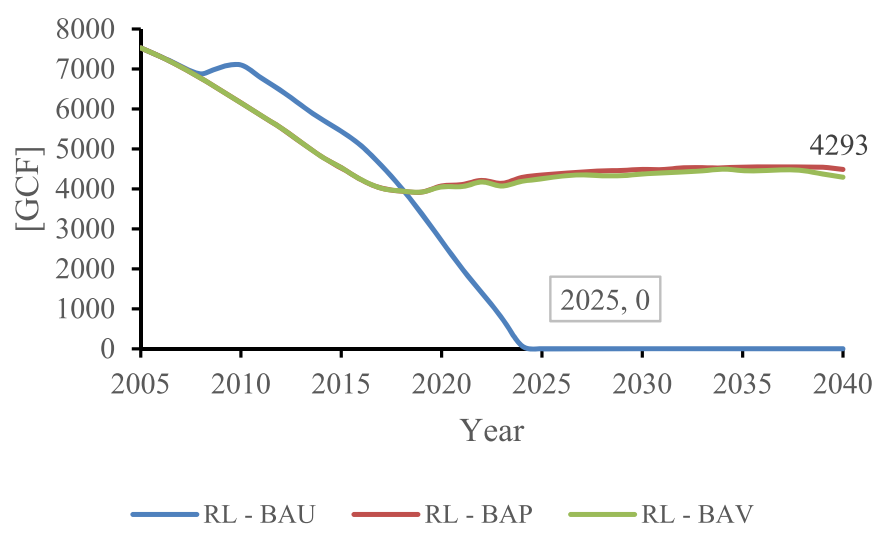

Fig. 16. Behavior of reserves level $(R L)$ under three different scenarios. 


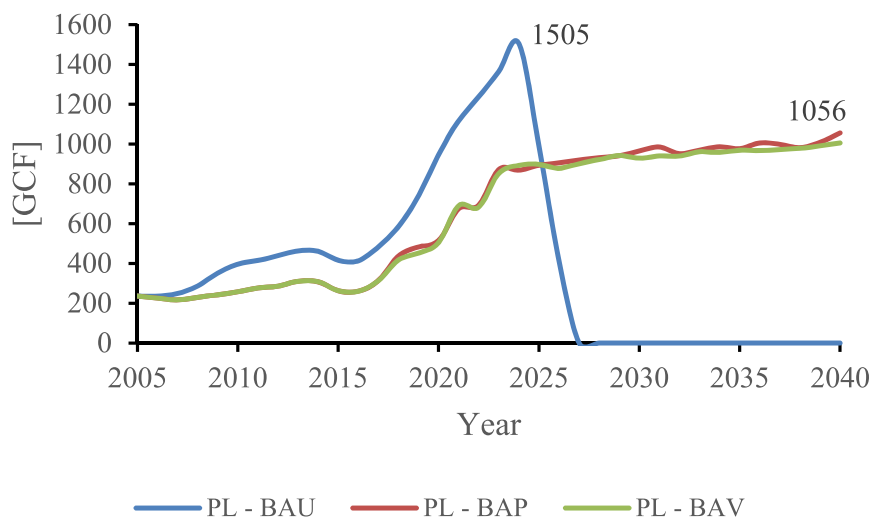

Fig. 17. Behavior of production level $(P L)$ under three different scenarios.

scenario, the production level $(P L)$ reaches a maximum of 1505 [GCF] and subsequently falls to zero. In the BAP and BAV scenarios, this production level stabilizes at 1056 [GCF] (see Fig. 17).

The transport level (TL) in the BAU scenario reaches a maximum of 978 [GCF] and subsequently falls to zero given the shortages generated by the depletion of the level of reserves $(R L)$ (see Fig. 16). In the BAP scenario, the transport level reaches a maximum of 723 [GCF], subsequently, it shows a decrease due to the constant increase in demand (TD). Finally, in the BAV scenario (which considers a significant increase in demand), the transport level reaches a maximum of 718 [GCF] and subsequently reduces down to values close to zero. This could indicate the incapacity of the natural gas supply chain, due to the demand increase considered in this scenario (see Fig. 18).

\subsubsection{Demand variables}

Total demand (TD) is calculated under the three proposed scenarios (BAU, BAP and, BAV). The served demand $(S D)$ and the unmet demand $(U M)$ for each scenario are used as performance measures.

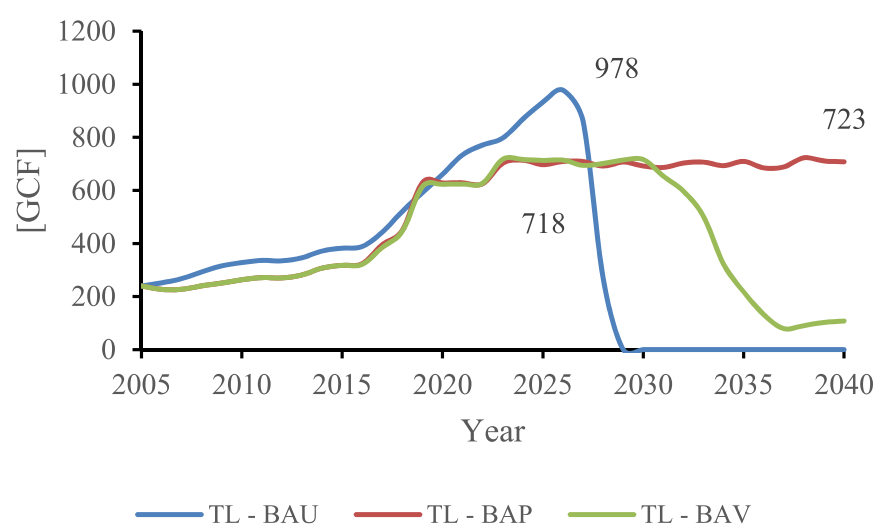

Fig. 18. Behavior of transport level $(T L)$ under three different scenarios.

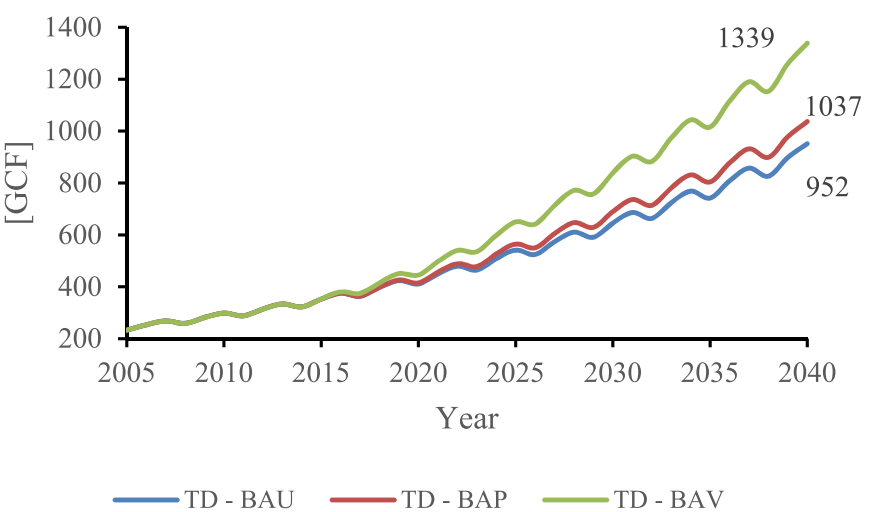

Fig. 19. Behavior of total demand (TD) under three different scenarios.

These are indicators of sustainable growth for the natural gas supply chain as they can establish if growth is attained under uninterruptedly gas-supplied conditions.

In all three scenarios, demand growth is expected. In the BAU scenario, it reaches a value of 952 [GCF] in the year 2040. As for the BAP scenario, due to the implementation of supply policies, the demand reaches a value of 1037 [GCF] in the year 2040. The BAV scenario analyzes the behavior of the model which shows an increase in demand of $36 \%$ (higher values than this increase in demand generate shortages of natural gas in the supply chain), which generates a maximum of 1339 [GCF] in the year 2040 (see Fig. 19).

The served demand $(S D)$ in the BAU scenario reaches a maximum of 592 [GCF] and subsequently falls to zero, as mentioned, due to the shortage generated by the depletion of reserves (see Fig. 16). In the BAP scenario, with a fluctuation due to the increase in demand (see Fig. 19), it reaches a maximum of 1008 [GCF]. In contrast, the BAV scenario has a better response due to the implementation of the supply policies and the increase in the demand, thereby reaching a maximum of 1264 [GCF] (see Fig. 20).

One of the main objectives of energy-related public policies is the uninterrupted supply to consumers. For this reason, the result

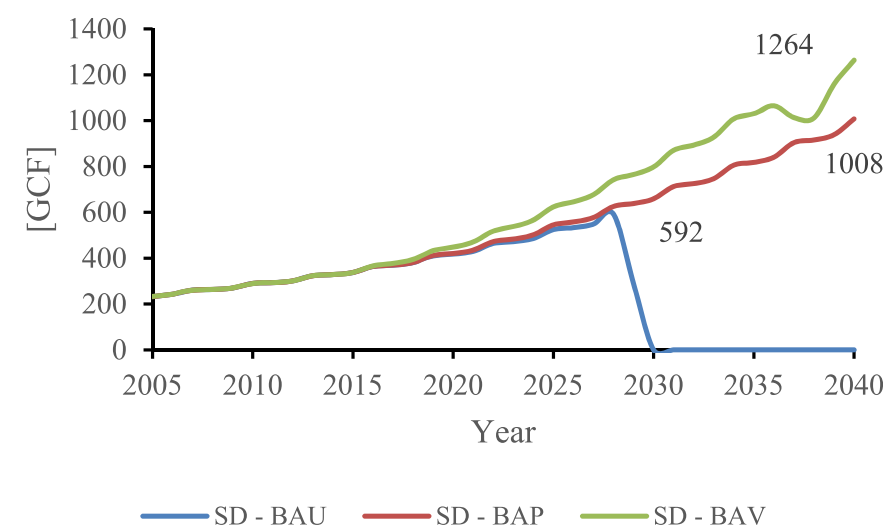

Fig. 20. Behavior of served demand $(S D)$ under three different scenarios. 


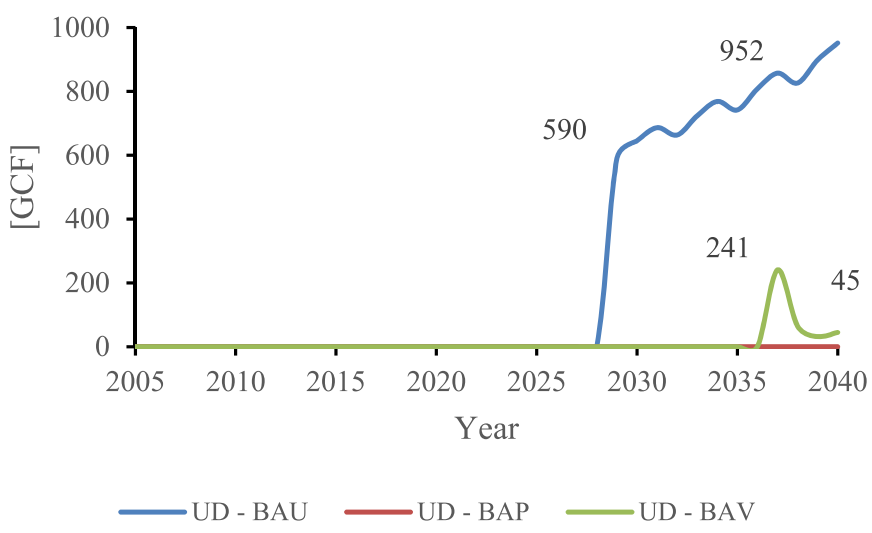

Fig. 21. Behavior of unmet demand (UD) under three different scenarios.

emerging from the implementation of the policies explored in this paper is expected to be zero in unmet demand (UD). The scenario that guarantees this condition is the BAP scenario, which indicates that the policies would respond to the estimated demand. In the BAU scenario, a value of 590 [GCF] is initially reached in the natural gas shortages, reaching a value of 952 [GCF] in the year 2040. In the BAV scenario, initially, shortages of 241 [GCF] are presented and subsequently, a value of 45 [GCF] is reached (see Fig. 21).

Simulations show that policies promote the sustainable growth of the natural gas industry. This is achieved by providing the correct signals for bringing just-in-time capacity investment through the supply chain, thus maintaining the appropriate reserve capacity levels along the chain links. Production and transport capacities of natural gas are shown to be aligned with consumption growth.

Policy keeps the level of reserves at reliable values. Production increases and stabilizes during the planning horizon. The transport level increases as a result of the policy signals; however, in the market development scenario, it decreases in the long-term, threatening outages. This implies the need for capacity expansion in the pre-transport links along the supply chain. In contrast, failure to implement policies for market development will lead to the depletion of reserves, production and transport levels from early 2025.

Natural gas demand grows at similar rates in all scenarios, except for the market development scenario, where it grows at higher rates. Shortages occur when policies are not applied, establishing that they are needed.

\section{Conclusions, limitations and future perspectives}

This paper proposes and discusses a model that combines the demand, transport, production and reserves of natural gas for the Colombian case, through a methodology, that enables us to observe the behavior of the supply of natural gas in a given time-interval, through the supply policies implementation and expected demand growth.

Although reserves of natural gas are declining rapidly in Colombia, this paper shows that this fuel can help secure the transition towards renewables by getting in place the appropriate policy that promotes exploration, discoveries and developments of natural gas in the country. The development of reserves is a key factor for promoting upstream investment along the natural gas supply chain (production, transport and demand).

This paper also shows that modeling policy for the sustainable growth of the natural gas supply chains may help understanding not only of how to promote exploration but also a balance of capacities investments over the other components along the gas supply chain. This structural approach supports the stages of design, planning and operation management of natural gas supply, improving the performance in the timely allocation of resources, enabling uninterrupted supply, demand satisfaction and growth of the natural gas market.

For the natural gas supply policy analysis, three different scenarios are presented in which different degrees of policy implementation and demand growth are combined. These scenarios consider the possibility that policy makers allocate resources to speed up the execution times of infrastructure projects, and also formulate policies in which there is greater or fewer reserve security in the supply.

Through the scenario evaluation, it is possible to observe the effect of the policies in the capacity generation, by increasing the discrepancy in supply needs between reserves, production and transport levels. These increases respond efficiently to demand requirements. These oscillations increase backward in the supply chain, in the case between transport and production levels, which is known as the bullwhip effect and has been widely studied by Forrester [17] in supply chain research by using SD.

Finally, the paper shows that if the appropriate policy that considers the natural gas supply is not in place, there is no guarantee of continued supply of natural gas, specifically in the no policy implementation and no demand growth (BAU) scenario. Results indicate that security of supply is not guaranteed in the long term, if policies focused on security of supply are not in place.

Some limitations for the development of this research center on the difficulty to obtain updated historical data. The data is reported in several units of measurement, which involves additional stages of validation prior to the development of the simulation models. In Colombia, there is no centralized information. Much of this is found in databases and reports of public and private actors operating in the natural gas sector. Many of these difficulties were solved with the support of Hydrocarbons Section of the UPME.

Future research will seek to guide the supply chain models in energy by using SD in the migration of conventional energy sources to sustainable energy sources, with a focus on the Colombian case.

\section{Declaration of competing interest}

The authors declare that they have no known competing financial interests or personal relationships that could have appeared to influence the work reported in this paper.

\section{CRediT authorship contribution statement}

Mauricio Becerra-Fernandez: Conceptualization, Methodology, Software, Validation, Formal analysis, Investigation, Resources, Data curation, Writing - original draft, Writing - review \& editing, Visualization. Federico Cosenz: Conceptualization, Methodology, Writing - review \& editing, Supervision. Isaac Dyner: Conceptualization, Methodology, Software, Validation, Formal analysis, Data curation, Writing - review \& editing, Supervision. 
Appendix A. Summary of the literature review on energy supply chain models

Table 6

Literature review of natural gas supply chain models.

\begin{tabular}{|c|c|c|c|c|}
\hline Modeling approach & Author & Year & Energy resource & Research subject \\
\hline \multirow[t]{6}{*}{ Optimization models } & $\begin{array}{l}\text { Cafaro DC, Grossmann } \\
\text { IE. }\end{array}$ & 2014 & Shale gas & Design and planning of the supply chain \\
\hline & Gao J. et al. & 2015 & Biomass-to-liquids & \\
\hline & Gao J, You F. & 2017 & Shale gas & Performance and optimal design of energy supply chains \\
\hline & Elia JA. et al. & 2014 & Heat, power, and liquid fuels & \\
\hline & Gao J, You F. & 2015 & Shale gas & Sustainable planning and optimization of the supply chain \\
\hline & Guerra OJ. et al. & 2016 & & \\
\hline \multirow[t]{4}{*}{ Optimization and simulation methods } & Hamedi M. et al. & 2009 & Natural gas & Planning activities in natural gas supply chain networks \\
\hline & Elia JA. et al. & 2014 & $\begin{array}{l}\text { Natural gas and natural gas } \\
\text { liquids }\end{array}$ & \\
\hline & Derosa SE, Allen DT. & 2015 & & \\
\hline & Elia JA. et al. & 2015 & & \\
\hline Bibliographic analysis & Espinoza Pérez AT. & 2016 & Bioenergetics & Supply chain design and management \\
\hline Economic model & Hoo PY. et al. & 2017 & & \\
\hline Network flow model & Jensen IG. et al. & 2017 & & \\
\hline Stochastic programming & Ghelichi Z. et al. & 2018 & & \\
\hline \multirow[t]{4}{*}{ Optimization model } & Bekkering J. et al. & 2018 & & \\
\hline & Werner A. et al. & 2014 & Liquefied natural gas & Strategic planning process in supply chain \\
\hline & Geng JB. et al. & 2017 & & \\
\hline & Bittante A. et al. & 2018 & & \\
\hline $\begin{array}{l}\text { Techno-economic and life cycle analyses } \\
\text { models }\end{array}$ & Sapkota K. et al. & 2018 & Natural gas & \\
\hline Optimization model & Tan SH, Barton PI. & 2017 & Shale gas & Supply chain planning \\
\hline Stochastic programming model & Chebeir J. & 2017 & & \\
\hline Optimization model & He L. et al. & 2018 & & \\
\hline Stochastic model & Chen Y. et al. & 2018 & & \\
\hline \multirow[t]{2}{*}{ Integrated model } & Jiang J. et al. & 2019 & Oil & Decision making for stakeholders \\
\hline & Rui Z. et al. & 2018 & & \\
\hline Literature review & Dujak D. & 2017 & Natural gas & Effective use of natural gas supply chain \\
\hline Dynamic model & Crow DJG. et al. & 2018 & & Emissions and environmental effects \\
\hline Probabilistic model & Balcombe P. & 2018 & & \\
\hline Montecarlo model & Hauck M. et al. & 2014 & & Natural gas for electricity generation \\
\hline \multirow[t]{5}{*}{ Optimization model } & Safarian S. et al. & 2013 & & Allocation of capacities in the supply of natural gas \\
\hline & Fan YY. et al. & 2017 & & \\
\hline & Mikolajková M. et al. & 2017 & & $\begin{array}{l}\text { Infrastructure for transportation and distribution of natural } \\
\text { gas }\end{array}$ \\
\hline & Mikolajková M. et al. & 2018 & & \\
\hline & Malinowski E. et al. & 2018 & Helium & Effects of the demand on supply chain \\
\hline
\end{tabular}

\section{Appendix B. Summary of the literature review on SD for energy supply}

Table 7

Literature review of SD models related.

\begin{tabular}{|c|c|c|c|}
\hline Author & Year & Energy resource & Research subject \\
\hline North MJ. et al. & 2015 & Natural gas and oil & Supply of natural gas \\
\hline Cai Z. et al. & 2010 & Helium & \\
\hline Ponzo R. el al. & 2011 & Natural gas & \\
\hline Bunn DW. et al. & 1997 & Natural gas and electricity & Energy market and natural gas \\
\hline Jingchun S. et al. & 2010 & Natural gas & \\
\hline Li J, Dong. et al. & 2011 & & \\
\hline Olaya Y, Dyner I. & 2005 & & Policy and decision-making processes \\
\hline Chyong Chi K. & 2009 & & \\
\hline Eker S, van Daalen E. & 2015 & Biomethane & \\
\hline Horschig T. et al. & 2016 & Bio-SNG & \\
\hline Bala BK. & 2006 & Biomass & Environmental impact of energy supply \\
\hline Howells M. et al. & 2010 & Electricity system & \\
\hline Yücel G, van Daalen C. & 2012 & & \\
\hline Eker S, Daalen E Van. & 2013 & Natural gas & \\
\hline Becerra-Fernandez M. et al. & 2019 & & Natural gas supply policy assessment \\
\hline Becerra-Fernandez M. et al. & 2018 & & \\
\hline Becerra-Fernandez M, Rodriguez-Yee R. & 2017 & & \\
\hline
\end{tabular}




\section{Appendix C. Equations of the model}

dt.

Demand_TD $(t)=$ Demand_TD $(t-d t)+($ Demand_growth_DG $) *$

INIT Demand_TD $=232.51$.

INFLOWS:

Demand_growth_DG $=\operatorname{IF}(\mathrm{BAV}=1) \mathrm{THEN}(\mathrm{IF}(\mathrm{TIME}<2016)$

THEN(Demand_aver-

age_increase_-

DAI*Demand_TD*Effect_of_consumer_price_on_demand_ECPD)

$\operatorname{ELSE}((-$

Demand_average_increase_DAI*Demand_TD*Potential_demand_PD)*Effect_of_consumer_price_on_demand_ECPD))ELSE(Demand_ average_increase_DAI*Demand_TD*Effect_of_consumer_price_ on_demand_ECPD)

Possible_reserves_PR $(\mathrm{t}) \quad=\quad$ Possible_reserves_PR( $\mathrm{t}$ $\mathrm{dt})+$ (New_reserves_development_NRD - Reserves_development_RD) *dt.

INIT Possible_reserves_PR $=1$.

INFLOWS:

New_reserves_development_NRD = Average_reserves_capacity_ increase_ARCI*Effect_of_wellhead_price_on_reserves_EWPR. OUTFLOWS:

Reserves_development_RD $=$ Possible_reserves_PR/

Time_for_reserves_development_TRD.

Production_capacity_PC $(\mathrm{t})=$ Production_capacity_PC( $\mathrm{t}$ $\mathrm{dt})+$ (Production_capacity_completion_PCC + Production_

policies_PP - Obsolete_production_capacity_OPC) * dt.

INIT Production_capacity_PC $=236$.

INFLOWS:

Production_capacity_completion_PCC $=$ Production_capacity_ under_construction_PCUC/

Time_for_capacity_constrution_in_production_TPCC.

Production_policies_PP $=\mathrm{IF}(\mathrm{BAP}=1) \mathrm{THEN}\left(\mathrm{P} \_2021+\mathrm{P} \_2023\right)$

$\operatorname{ELSE}(0)$

OUTFLOWS:

Obsolete_production_capacity_OPC = Production_capacity_PC/ Production_capacity_lifetime_PCL.

Production_capacity_under_construction_PCUC(t) = Production_ capacity_under_construction_PCUC(t - dt) + (New_produc tion_capacity_construction_NPCC - Production_capacity_completion_PCC) $*$ dt.

INIT Production_capacity_under_construction_PCUC $=1$.

INFLOWS:

New_production_capacity_construction_NPCC = Average_ production_capacity_increase_APCI*Effect_of_wellhead_price_ on_production_EWPP.

OUTFLOWS:

Production_capacity_completion_PCC = Production_capacity_ under_construction_PCUC/

Time_for_capacity_constrution_in_production_TPCC.

Production_level_PL(t) = Production_level_PL(t - dt) + (Production_level_increase_PLI - Transport_level_increase_TLI) * dt.

INIT Production_level_PL $=236$.

INFLOWS:

Production_level_increase_PLI $=\mathrm{IF}(\mathrm{BAU}=1) \mathrm{THEN}($ Usual_production_increas_UPI*Production_fluctuation_PF)ELSE(-

IF(Production_capacity_PC $>$ Production_level_PL)

THEN((MAX(Production_capacity_PC,Usual_production_increas_-

UPI)*Production_fluctuation_PF))ELSE(0))

OUTFLOWS:

Transport_level_increase_TLI = IF(BAU = 1$)$
THEN(Usual_transport_increase_UTI*Transport_fluctuation_TF) ELSE(IF(Transport_capacity_TC>Transport_level_TL)

THEN((MAX(Transport_capacity_TC,Usual_transport_increase_UT-

I)*Transport_fluctuation_TF))ELSE(0))

P_BAU $(\mathrm{t})=$ P_BAU $(\mathrm{t}-\mathrm{dt})+($ Normal_P $) * \mathrm{dt}$.

INIT P_BAU $=236$.

INFLOWS:

Normal_P $=0.0602 * P \_B A U$.

Reserves_capacity_RC(t) = Reserves_capacity_RC(t -

$\mathrm{dt})+$ (Reserves_development_RD + Reserves_policies_RP - Obso-

lete_reserves_capacity_ORC) $* \mathrm{dt}$.

INIT Reserves_capacity_RC $=7527$.

INFLOWS:

Reserves_development_RD $=$ Possible_reserves_PR/Time_for_ reserves_development_TRD.

Reserves_policies_RP $=\mathrm{IF}(\mathrm{BAP}=1) \mathrm{THEN}\left(\mathrm{STEP}\left(\mathrm{R} \_t h r o u g h \_20 /\right.\right.$

R_implementation_time,2017))ELSE(0)

OUTFLOWS:

Obsolete_reserves_capacity_ORC = Reserves_capacity_RC/

Reserves_capacity_lifetime_RCL.

Reserves_level_RL $(t)=$ Reserves_level_RL(t - dt) + (Reserves_

level_increase_RLI - Production_level_increase_PLI) * dt.

INIT Reserves_level_RL $=7527$.

INFLOWS:

Reserves_level_increase_RLI $=$ IF(BAU $=1)$ THEN(Reserves_fluctuation_RF)ELSE(-

IF(Reserves_capacity_RC $>$ (Reserves_le-

vel_RL+Reserves_fluctuation_RF))THEN(Reserves_capacity_RC-

(Reserves_level_RL+Reserves_fluctuation_RF))ELSE(0))

OUTFLOWS:

Production_level_increase_PLI $=\mathrm{IF}(\mathrm{BAU}=1) \mathrm{THEN}($ Usual_production_increas_UPI*Production_fluctuation_PF)ELSE(-

IF(Production_capacity_PC $>$ Production_level_PL)

THEN((MAX(Production_capacity_PC,Usual_production_increas_-

UPI)*Production_fluctuation_PF))ELSE(0))

Transport_capacity_TC $(\mathrm{t})=$ Transport_capacity_TC $(\mathrm{t}-\mathrm{dt})+$ (Transport_capacity_completion_TCC + Transport_policies_TP Obsolete_transport_capacity_OTC) * dt.

INIT Transport_capacity_TC $=239.805$.

INFLOWS:

Transport_capacity_completion_TCC = Transport_capacity_ under_construction_TCUC.

/Time_for_transport_capacity_construction_TTCC.

Transport_policies_TP $=\operatorname{IF}($ BAP $=1)$ THEN(T_2017+T_2018+

T_2019+T_2023)ELSE(0)

OUTFLOWS:

Obsolete_transport_capacity_OTC = Transport_capacity_TC/ Transport_capaity_lifetime_TCL.

Transport_capacity_under_construction_TCUC $(\mathrm{t})=$ Transport capacity_under_construction_TCUC(t - dt) + (New_transport_ capacity_construction_NTCC - Transport_capacity_completion_ $\mathrm{TCC}) * \mathrm{dt}$.

INIT Transport_capacity_under_construction_TCUC $=1$.

INFLOWS:

New_transport_capacity_construction_NTCC $=$ Average transport_capacity_increase_ATCI*Effect_of_consumer_price_on_

transport_ECPT.

OUTFLOWS:

Transport_capacity_completion_TCC = Transport_capacity_ under_construction_TCUC.

/Time_for_transport_capacity_construction_TTCC.

Transport_level_TL(t) $=$ Transport_level_TL $(\mathrm{t}-\mathrm{dt})+($ Transport_level_increase_TLI - Served_demand_SD) $*$ dt.

INIT Transport_level_TL $=239.805$.

INFLOWS: 
Transport_level_increase_TLI $=$ IF(BAU $=1)$ THEN(Usual_transport_increase_UTI*Transport_fluctuation_TF)ELSE(-

IF(Transport_capacity_TC > Transport_level_TL)

THEN((MAX(Transport_capacity_TC,Usual_transport_increase_UT-

I)*Transport_fluctuation_TF))ELSE(0))

OUTFLOWS:

Served_demand_SD $=$ Natural_Gas_Demand_NGD.

T_BAU $(\mathrm{t})=\mathrm{T} \_\mathrm{BAU}(\mathrm{t}-\mathrm{dt})+($ Normal_T $) * \mathrm{dt}$.

INIT T_BAU $=239.85$.

INFLOWS:

Normal_T $=0.0462 *$ T_BAU.

Average_production_capacity_increase_APCI $=18.3$.

Average_reserves_capacity_increase_ARCI $=-208.4$.

Average_transport_capacity_increase_ATCI $=13.8$.

$\mathrm{BAP}=1$.

$\mathrm{BAU}=1$.

$\mathrm{BAV}=1$.

Consumer_price_CP $=$ GRAPH(Supply_margin_SM)

(0.1, 20.0), (0.45, 18.7), (0.8, 16.6), (1.15, 15.1), (1.50, 13.5), (1.85,

$12.2),(2.20,11.1),(2.55,10.2),(2.90,9.34),(3.25,8.57),(3.60,7.90)$,

(3.95, 7.12), (4.30, 6.50), (4.65, 5.78), (5.00, 5.21)

Demand_average_increase_DAI $=0.0414$.

Demand_fluctuation_DF $=$ GRAPH(TIME)

(2006, 1.00), (2007, 1.05), (2008, 1.08), (2009, 1.00), (2010, 1.05), (2011, 1.08), (2012, 1.00), (2013, 1.05), (2014, 1.08), (2015, 1.00), (2016, 1.05), (2017, 1.08), (2018, 1.00), (2019, 1.05), (2020, 1.08), (2021, 1.00), (2022, 1.05), (2023, 1.08), (2024, 1.00), (2025, 1.05), (2026, 1.08), (2027, 1.00), (2028, 1.05), (2029, 1.08), (2030, 1.00), (2031, 1.05), (2032, 1.08), (2033, 1.00), (2034, 1.05), (2035, 1.08), (2036, 1.00), (2037, 1.05), (2038, 1.08), (2039, 1.00), (2040, 1.05), (2041, 1.08), (2042, 1.00)

Effect_of_consumer_price_on_demand_ECPD = GRAPH (Consumer_price_CP)

(5.00, 1.60), (5.79, 1.58), (6.58, 1.55), (7.37, 1.52), (8.16, 1.48), (8.95, 1.43), (9.74, 1.40), (10.5, 1.35), (11.3, 1.32), (12.1, 1.25), (12.9, $1.19),(13.7,1.12),(14.5,1.06),(15.3,0.982),(16.1,0.871),(16.8$, 0.739), (17.6, 0.586), (18.4, 0.449), (19.2, 0.322), (20.0, 0.1)

Effect_of_consumer_price_on_transport_ECPT = GRAPH (Consumer_price_CP)

(5.00, 0.01), (5.79, 0.695), (6.58, 0.998), (7.37, 1.23), (8.16, 1.50), (8.95, 1.73), (9.74, 1.91), (10.5, 2.03), (11.3, 2.21), (12.1, 2.34), (12.9, $2.45),(13.7,2.51),(14.5,2.64),(15.3,2.71),(16.1,2.82),(16.8,2.86)$,

(17.6, 2.95), (18.4, 3.01), (19.2, 3.09), (20.0, 3.18)

Effect_of_wellhead_price_on_production_EWPP = GRAPH (Wellhead_price_WP)

(1.50, 0.01), (1.68, 0.437), (1.87, 0.807), (2.05, 1.10), (2.24, 1.30), (2.42, 1.50), (2.61, 1.66), (2.79, 1.87), (2.97, 2.02), (3.16, 2.21), (3.34, 2.34), (3.53, 2.41), (3.71, 2.55), (3.89, 2.71), (4.08, 2.78), (4.26, 2.93),

(4.45, 3.05), (4.63, 3.12), (4.82, 3.23), (5.00, 3.30)

Effect_of_wellhead_price_on_reserves_EWPR = GRAPH

(Wellhead_price_WP)

(1.50, 0.001), (1.85, 0.00336), (2.20, 0.0055), (2.55, 0.00666), (2.90, 0.00797), (3.25, 0.00861), (3.60, 0.00918), (3.95, 0.00949), (4.30, 0.00987), (4.65, 0.00994), (5.00, 0.01)

Extaction_margin_EM = (Possible_reserves_PR+Reserves_ capacity_RC)/(Production_capacity_under_construction_PCUC+

Production_capacity_PC)

Natural_Gas_Demand_NGD

Demand_TD*Demand_fluctuation_DF.

Potential_demand_PD $=1.1$.

Production_capacity_lifetime_PCL $=20$.

Production_fluctuation_PF $=$ GRAPH(TIME)

(2006, 1.00), (2007, 1.10), (2008, 1.14), (2009, 1.25), (2010, 1.20), (2011, 1.05), (2012, 0.9), (2013, 0.95), (2014, 0.99), (2015, 0.8), (2016, $0.65),(2017,1.00),(2018,1.10),(2019,1.14),(2020,1.25),(2021,1.20)$,
(2022, 1.05), (2023, 0.9), (2024, 0.95), (2025, 0.99), (2026, 0.8), (2027, 0.65), (2028, 1.00), (2029, 1.10), (2030, 1.14), (2031, 1.25), (2032, 1.20), (2033, 1.05), (2034, 0.9), (2035, 0.95), (2036, 0.99), (2037, 0.8), (2038, 0.65), (2039, 1.00), (2040, 1.10), (2041, 1.14), $(2042,1.25)$

P_2021 = PULSE $(146,2021,0)$

P_2023 = PULSE $(160.6,2023,0)$

Reserves_capacity_lifetime_RCL $=20$.

Reserves_fluctuation_RF $=$ GRAPH(TIME)

(2006, 0.00), (2007, 76.0), (2008, 24.0), (2009, 250), (2010, 800), (2011, 0.00), (2012, 0.00), (2013,0.00), (2014, 0.00), (2015, 0.00), (2016, 0.00), (2017, 0.00), (2018, 0.00), (2019,0.00), (2020,0.00), (2021, 0.00), (2022, 0.00), (2023, 0.00), (2024, 0.00), (2025, 0.00), (2026, 0.00), (2027, 0.00), (2028, 0.00), (2029, 0.00), (2030, 0.00), (2031, 0.00), (2032, 0.00), (2033, 0.00), (2034, 0.00), (2035, 0.00), (2036, 0.00), (2037, 0.00), (2038, 0.00), (2039, 0.00), (2040, 0.00), (2041, 0.00), (2042, 0.00)

R_implementation_time $=20$.

R_through_20 = 6040 .

Supply_margin_SM = ((Production_capacity_PC+Transport capacity_TC)/2)/Natural_Gas_Demand_NGD.

Time_for_capacity_constrution_in_production_TPCC $=3$.

Time_for_reserves_development_TRD $=6$.

Time_for_transport_capacity_construction_TTCC $=3$.

Transport_capaity_lifetime_TCL $=20$.

Transport_fluctuation_TF $=$ GRAPH(TIME)

(2006, 1.00), (2007, 1.08), (2008, 1.08), (2009, 1.08), (2010, 1.00), (2011, 1.05), (2012, 0.9), (2013, 0.95), (2014, 1.02), (2015, 0.97), (2016, 0.9), (2017, 1.00), (2018, 1.08), (2019, 1.08), (2020,1.08), (2021, 1.00), (2022, 1.05), (2023, 0.9), (2024, 0.95), (2025, 1.02), (2026, $0.97),(2027,0.9),(2028,1.00),(2029,1.08),(2030,1.08),(2031,1.08)$, (2032, 1.00), (2033, 1.05), (2034, 0.9), (2035, 0.95), (2036, 1.02), (2037, 0.97), (2038, 0.9), (2039, 1.00), (2040, 1.08), (2041, 1.08), $(2042,1.08)$

T_2017 = PULSE $(27.5,2017,0)$

$\mathrm{T} \_2018=$ PULSE $(7.9,2018,0)$

$\mathrm{T} \_2019=$ PULSE $(167.3,2019,0)$

$\mathrm{T} \_2023=$ PULSE $(78.2,2023,0)$

Unmet_demand_UD $=$ IF((Natural_Gas_Demand_NGD-Served_demand_SD) < 0)THEN(0)ELSE(Natural_Gas_Demand_NGDServed_demand_SD)

Usual_production_increas_UPI $=$ P_BAU.

Usual_transport_increase_UTI $=$ T_BAU.

Wellhead_price_WP $=$ GRAPH(Extaction_Margin_EM)

(1.00, 5.00), (4.50, 4.70), (8.00, 4.33), (11.5, 3.91), (15.0, 3.53), (18.5, 3.21), (22.0, 2.92), (25.5, 2.68), (29.0, 2.45), (32.5, 2.29), (36.0, 2.09), (39.5, 1.95), (43.0, 1.79), (46.5, 1.63), (50.0, 1.51)

\section{References}

[1] OECD. Towards green growth. 2011.

[2] IGU. The role of natural gas in the energy transition. 2018.

[3] BP. BP statistical review of world energy 2018. 2018.

[4] UPME. Transitory plan of natural gas supply. 2016.

[5] UPME. Monthly report on generating variables and the Colombian electric market - august 2018. 2018.

[6] International Gas Union. Eurogas. The role of natural gas in a sustainable energy market. 2010.

[7] UPME. Balance of supply and demand of natural gas 2017. 2017.

[8] Becerra-Fernandez M, González La Rotta EC, Cosenz F, Dyner I. Supporting the natural gas supply chain public policies through simulation methods: a dynamic performance management approach. In: Rodriguez-Molano JI, editor. Figueroa-garcía JC, lópez-santana ER. Cham: Springer International Publishing; 2018. p. 363-76. https://doi.org/10.1007/978-3-030-00350-0_31. https:// link.springer.com/chapter/.

[9] Becerra-Fernandez M, González La Rotta EC, Cosenz F, Dyner I. Demand and supply model for the natural gas supply chain in Colombia. In: Li L, Hasegawa K, Tanaka S, editors. Methods appl. Model. Simul. Complex syst. Singapore: Springer Singapore; 2018. p. 220-31. 
[10] Becerra-Fernandez M, Ibarra-Vega D, Redondo JM, Dyner I. Modeling for the evaluation of public policy alternatives in the supply chain of natural gas in Colombia. In: Figueroa-García JC, Duarte-González M, Jaramillo-Isaza S, Orjuela-Cañon AD, Díaz-Gutierrez Y, editors. Appl. Comput. Sci. Eng. Cham: Springer International Publishing; 2019. p. 709-21.

[11] Becerra-Fernandez M, Rodriguez-Yee R. Selection of alternatives for the natural gas supply in Colombia using the analytic hierarchy process. Ingenieria 2017;22. https://doi.org/10.14483/udistrital.jour.reving.2017.2.a02.

[12] Olaya Y, Dyner I. Modelling for policy assessment in the natural gas industry. J Oper Res Soc 2005;56:1122-31. https://doi.org/10.1057/ palgrave.jors.2601895.

[13] Chyong Chi K, Nuttall WJ, Reiner DM. Dynamics of the UK natural gas industry: system dynamics modelling and long-term energy policy analysis. Technol Forecast Soc Change 2009;76:339-57. https://doi.org/10.1016/ j.techfore.2008.06.002.

[14] Eker S, van Daalen E. A model-based analysis of biomethane production in The Netherlands and the effectiveness of the subsidization policy under uncertainty. Energy Pol 2015;82:178-96. https://doi.org/10.1016/ j.enpol.2015.03.019.

[15] Horschig T, Billig E, Thrän Db. Model-based estimation of market potential for Bio-SNG in the German biomethane market until 2030 within a system dynamics approach. Agron Res 2016;14:754-67.

[16] Sterman JD. Business dynamics systems thinking and modeling for a complex world. first ed. USA: McGraw-Hill; 2000.

[17] Forrester JW. Industrial dynamics. J Oper Res Soc 1997;48:1037-41. https:/ doi.org/10.1057/palgrave.jors.2600946.

[18] Robledo S, Osorio GA, López C. Networking en pequeña empresa: una revisión bibliográfica utilizando la teoria de grafos. Rev Vínculos 2014;11:6-16. https://doi.org/10.14483/issn.2322-939X.

[19] Cafaro DC, Grossmann IE. Strategic planning, design, and development of the shale gas supply chain network. AIChE J 2014;60:2122-42. https://doi.org/ 10.1002/aic.14405.

[20] Gao J, You F. Optimal design and operations of supply chain networks for water management in shale gas production: MILFP model and algorithms for the water-energy nexus. AIChE J 2015;61:1184-208. https://doi.org/10.1002/ aic.14705.

21] You F, Wang B. Life cycle optimization of biomass-to-liquid supply chain with distributed-centralized processing networks. Ind Eng Chem Res 2011;50 10102-27. https://doi.org/10.1021/ie200850t.

[22] Gao J, You F. Design and optimization of shale gas energy systems: overview, research challenges, and future directions. Comput Chem Eng 2017;106: 699-718. https://doi.org/10.1016/j.compchemeng.2017.01.032.

[23] Elia JA, Floudas CA. Energy supply chain optimization of hybrid feedstock processes: a review. Annu Rev Chem Biomol Eng 2014;5:147-79. https: doi.org/10.1146/annurev-chembioeng-060713-040425.

[24] Gao J, You F. Shale gas supply chain design and operations toward better economic and life cycle environmental performance: MINLP model and global optimization algorithm. ACS Sustainable Chem Eng 2015;3:1282-91. https:/ doi.org/10.1021/acssuschemeng.5b00122.

[25] Guerra OJ, Calderón AJ, Papageorgiou LG, Siirola JJ, Reklaitis GV. An optimization framework for the integration of water management and shale gas supply chain design. Comput Chem Eng 2016;92:230-55. https://doi.org 10.1016/j.compchemeng.2016.03.025

[26] Hamedi M, Zanjirani Farahani R, Husseini MM, Esmaeilian GR. A distribution planning model for natural gas supply chain: a case study. Energy Pol 2009;37:799-812. https://doi.org/10.1016/j.enpol.2008.10.030.

[27] Elia JA, Baliban RC, Floudas CA. Nationwide, regional, and statewide energy supply chain optimization for natural gas to liquid transportation fuel (GTL) systems. Ind Eng Chem Res 2014;53:5366-97. https://doi.org/10.1021/ ie401378r.

[28] Derosa SE, Allen DT. Impact of natural gas and natural gas liquids supplies on the United States chemical manufacturing industry: production cost effects and identification of bottleneck intermediates. ACS Sustainable Chem Eng 2015;3:451-9. https://doi.org/10.1021/sc500649k.

[29] Elia JA, Li J, Floudas CA. Strategic planning optimization for natural gas to liquid transportation fuel (GTL) systems. Comput Chem Eng 2015;72:109-25. https://doi.org/10.1016/j.compchemeng.2014.04.010.

[30] Espinoza Pérez AT, Camargo M, Narváez Rincón PC, Alfaro Marchant M. Key challenges and requirements for sustainable and industrialized biorefinery supply chain design and management: a bibliographic analysis. Renew Sustain Energy Rev 2017;69:350-9. https://doi.org/10.1016/j.rser.2016.11.084.

[31] Hoo PY, Hashim H, Ho WS. Opportunities and challenges: landfill gas to biomethane injection into natural gas distribution grid through pipeline. J Clean Prod 2018;175:409-19. https://doi.org/10.1016/j.jclepro.2017.11.193.

[32] Jensen IG, Münster M, Pisinger D. Optimizing the supply chain of biomass and biogas for a single plant considering mass and energy losses. Eur J Oper Res 2017;262:744-58. https://doi.org/10.1016/j.ejor.2017.03.071.

[33] Ghelichi Z, Saidi-Mehrabad M, Pishvaee MS. A stochastic programming approach toward optimal design and planning of an integrated green biodiesel supply chain network under uncertainty: a case study. Energy 2018;156:661-87. https://doi.org/10.1016/j.energy.2018.05.103.

[34] Bekkering J, Hengeveld EJ, van Gemert WJT, Broekhuis AA. Designing a green gas supply to meet regional seasonal demand - an operations research case study. Appl Energy 2015;143:348-58. https://doi.org/10.1016/ j.apenergy.2015.01.034.
[35] Werner A, Uggen KT, Fodstad M, Lium AG, Egging R. Stochastic mixed-integer programming for integrated portfolio planning in the LNG supply chain. Energy J 2014;35:79-97. https://doi.org/10.5547/01956574.35.1.5.

[36] Geng JB, Ji Q, Fan Y, Shaikh F. Optimal LNG importation portfolio considering multiple risk factors. J Clean Prod 2017;151:452-64. https://doi.org/10.1016/ j.jclepro.2017.03.053.

[37] Bittante A, Pettersson F, Saxén H. Optimization of a small-scale LNG supply chain. Energy 2018;148:79-89. https://doi.org/10.1016/j.energy.2018.01.120.

[38] Sapkota K, Oni AO, Kumar A. Techno-economic and life cycle assessments of the natural gas supply chain from production sites in Canada to north and southwest Europe. J Nat Gas Sci Eng 2018;52:401-9. https://doi.org/10.1016/ j.jngse.2018.01.048.

[39] Tan SH, Barton PI. Optimal shale oil and gas investments in the United States. Energy 2017;141:398-422. https://doi.org/10.1016/j.energy.2017.09.092.

[40] Chebeir J, Geraili A, Romagnoli J. Development of shale gas supply chain network under market uncertainties. Energies 2017;10. https://doi.org/ 10.3390/en10020246.

[41] He L, Chen Y, Li J. A three-level framework for balancing the tradeoffs among the energy, water, and air-emission implications within the life-cycle shale gas supply chains. Resour Conserv Recycl 2018;133:206-28. https://doi.org/ 10.1016/j.resconrec.2018.02.015.

[42] He L, Chen Y, Ren L, Li J, Liu L. Synergistic management of flowback and produced waters during the upstream shale gas operations driven by noncooperative stakeholders. J Nat Gas Sci Eng 2018;52:591-608. https:/| doi.org/10.1016/j.jngse.2018.02.018.

[43] Chen Y, He L, Zhao H, Li J. Energy-environmental implications of shale gas extraction with considering a stochastic decentralized structure. Fuel 2018;230:226-43. https://doi.org/10.1016/j.fuel.2018.05.012.

[44] Jiang J, Rui Z, Hazlett R, Lu J. An integrated technical-economic model for evaluating CO2 enhanced oil recovery development. Appl Energy 2019;247: 190-211. https://doi.org/10.1016/j.apenergy.2019.04.025.

[45] Rui Z, Wang X, Zhang Z, Lu J, Chen G, Zhou X, et al. A realistic and integrated model for evaluating oil sands development with Steam Assisted Gravity Drainage technology in Canada. Appl Energy 2018;213:76-91. https:// doi.org/10.1016/j.apenergy.2018.01.015.

[46] Dujak D. Mapping of natural gas supply chains: literature review. Proc. Int. Sci. Conf. Bus. Logist. Mod. Manag. 2017:293-310.

[47] Crow DJG, Giarola S, Hawkes AD. A dynamic model of global natural gas supply. Appl Energy 2018;218:452-69. https://doi.org/10.1016/ j.apenergy.2018.02.182.

[48] Balcombe P, Brandon NP, Hawkes AD. Characterising the distribution of methane and carbon dioxide emissions from the natural gas supply chain. J Clean Prod 2018;172:2019-32. https://doi.org/10.1016/ j.jclepro.2017.11.223.

[49] Hauck M, Steinmann ZJN, Laurenzi IJ, Karuppiah R, Huijbregts MAJ. How to quantify uncertainty and variability in life cycle assessment: the case of greenhouse gas emissions of gas power generation in the US. Environ Res Lett 2014:9:074005. https://doi.org/10.1088/1748-9326/9/7/074005.

[50] Safarian S, Saboohi Y, Kateb M. Evaluation of energy recovery and potential of hydrogen production in Iranian natural gas transmission network. Energy Pol 2013;61:65-77. https://doi.org/10.1016/j.enpol.2013.05.002.

[51] Fan YY, Lee A, Parker N, Scheitrum D, Jaffe AM, Dominguez-Fans R, et al. Geospatial, temporal and economic analysis of alternative fuel infrastructure: the case of freight and US natural gas markets. Energy J 2017;38:199-230. https://doi.org/10.5547/01956574.38.6.yfan.

[52] Mikolajková M, Saxén H, Pettersson F. Linearization of an MINLP model and its application to gas distribution optimization. Energy 2018;146:156-68. https://doi.org/10.1016/j.energy.2017.05.185.

[53] Mikolajková M, Saxén H, Pettersson F. Mixed integer linear programming optimization of gas supply to a local market. Ind Eng Chem Res 2018;57: 5951-65. https://doi.org/10.1021/acs.iecr.7b04197.

[54] Malinowski E, Karwan MH, Pinto JM, Sun L. A mixed-integer programming strategy for liquid helium global supply chain planning. Transport Res Part E Logist Transp Rev 2018;110:168-88. https://doi.org/10.1016/ j.tre.2017.12.014.

[55] North MJ, Murphy JT, Sydelko P, Martinez-Moyano I, Sallach DL, Macal CM. Integrated modeling of conflict and energy. In: 2015 winter simul. Conf., IEEE; 2015. p. 2499-510. https://doi.org/10.1109/WSC.2015.7408360.

[56] Cai Z, Clarke RH, Glowacki BA, Nuttall WJ, Ward N. Ongoing ascent to the helium production plateau-Insights from system dynamics. Resour Pol 2010;35:77-89. https://doi.org/10.1016/j.resourpol.2009.10.002.

[57] Ponzo R, Dyner I, Arango S, Larsen ER. Regulation and development of the Argentinean gas market. Energy Pol 2011;39:1070-9. https://doi.org/ 10.1016/j.enpol.2010.11.009.

[58] Bunn DW, Dyner I, Larsen ER. Modelling latent market power across gas and electricity markets. Syst Dynam Rev 1997;13:271-88. https://doi.org/ 10.1002/(SICI)1099-1727(199724)13:4<271::AID-SDR131>3.0.CO;2-3.

[59] Jingchun S, Ding L, Fan W. The simulated system dynamics analysis of the natural gas supply and demand. Kybernetes 2010;39:1262-9. https://doi.org/ $10.1108 / 03684921011063547$.

[60] Li J, Dong X, Shangguan J, Hook M. Forecasting the growth of China's natural gas consumption. Energy 2011;36:1380-5. https://doi.org/10.1016/ j.energy.2011.01.003.

[61] Chyong Chi K, Nuttall WJ, Reiner DM. Dynamics of the UK natural gas industry: system dynamics modelling and long-term energy policy analysis. 
Technol Forecast Soc Change 2009;76:339-57. https://doi.org/10.1016/ j.techfore.2008.06.002.

[62] Eker S, van Daalen E. A model-based analysis of biomethane production in The Netherlands and the effectiveness of the subsidization policy under uncertainty. Energy Pol 2015;82:178-96. https://doi.org/10.1016 j.enpol.2015.03.019.

[63] Bala BK. Computer modelling of energy and environment for Bangladesh. Int Agric Eng J 2006;15:151-60.

[64] Howells M, Jeong K, Langlois L, Lee MK, Nam K-Y, Rogner HH. Incorporating macroeconomic feedback into an energy systems model using an IO approach: evaluating the rebound effect in the Korean electricity system. Energy Pol 2010;38:2700-28. https://doi.org/10.1016/j.enpol.2008.10.054.

[65] Yücel G, van Daalen C. A simulation-based analysis of transition pathways for the Dutch electricity system. Energy Pol 2012;42:557-68. https://doi.org/ 10.1016/j.enpol.2011.12.024.

[66] Eker S, Daalen E Van. Investigating the effects of uncertainties in the upstream gas sector. Int J Syst Syst Eng 2013;4:99. https://doi.org/10.1504/ IJSSE.2013.056290.

[67] UPME. Indicative plan of natural gas supply - 2016. 2016.

[68] Whelan J, Forrester JW. Economic supply \& demand, vol. 7. MIT Syst Dyn Educ Proj; 1996.

[69] Cardenas LM, Franco CJ, Dyner I. Assessing emissions-mitigation energy policy under integrated supply and demand analysis: the Colombian case. J Clean Prod 2016;112:3759-73. https://doi.org/10.1016/j.jclepro.2015.08.089.

70] Sterman JD. Booms, busts, and beer. Understanding the dynamics of supply chains. Handb Behav Oper Manag Soc Psychol Dyn Prod Serv Settings 2015: 203-35.

[71] Simon HA. Administrative behaviour. Aust J Publ Adm 1950;9:241-5. https:// doi.org/10.1111/j.1467-8500.1950.tb01679.x.

[72] Colombian oil and gas information system; SIPG. Natural gas demand. 2017. http://www.sipg.gov.co/Inicio/GasNatural/Estadisticas/Demanda/tabid/122/ language/es-CO/Default.aspx. [Accessed 4 April 2019]. 